\title{
Sleep problems in preschoolers with autism spectrum disorders are associated with sensory sensitivities and thalamocortical overconnectivity
}

Linke, A.C. ${ }^{1}$, Chen, B. ${ }^{1,2}$, Olson, L. ${ }^{1,2}$, Ibarra, C. ${ }^{1}$, Fong, C. ${ }^{1,2}$, Reynolds, S. ${ }^{1}$, Apostol, M. ${ }^{1}$, Kinnear, M.K. ${ }^{1}$, Müller, R.-A. ${ }^{1,2} \&$ Fishman, I. ${ }^{1,2}$

${ }^{1}$ Brain Development Imaging Laboratories, Department of Psychology, San Diego State University, San Diego, CA, United States

${ }^{2}$ San Diego State University/University of California San Diego Joint Doctoral Program in Clinical Psychology, San Diego, CA, United States

Corresponding Author:

Annika Linke

Brain Development Imaging Laboratories, Department of Psychology

San Diego State University, 6363 Alvarado Ct., Suite 200, San Diego, CA 92120

Email: alinke@sdsu.edu 


\begin{abstract}
Projections between the thalamus and sensory cortices are established early in development and play an important role in sleep regulation as well as in relaying sensory information to cortex. Atypical thalamocortical functional connectivity frequently observed in children with autism spectrum disorders (ASD) might therefore be linked to sensory and sleep problems common in ASD. Here we investigated the relationship between auditory-thalamic functional connectivity measured during natural sleep fMRI, sleep problems, and sound sensitivities in 70 toddlers and preschoolers (1.5 to 5-year-olds) with ASD compared to a matched group of 46 typically developing (TD) children. In children with ASD, sleep problems and sensory sensitivities were positively correlated, and increased sleep latency was associated with overconnectivity between the thalamus and auditory cortex in a subsample with high quality MRI data ( $n=29)$. Additionally, auditory cortex BOLD signal amplitude was elevated in children with ASD, potentially reflecting reduced sensory gating or a lack of auditory habituation during natural sleep. These findings indicate that atypical thalamocortical functional connectivity can be detected early in development and may play a crucial role in sleep problems and sensory sensitivities in ASD.
\end{abstract}




\section{Introduction}

Autism spectrum disorders (ASD) are neurodevelopmental disorders characterized by sociocommunicative deficits, restricted and repetitive behaviors and interests, and sensory sensitivities (American Psychiatric Association, 2013). There is no known single etiology for ASD, but increasing evidence suggests that autism originates early in development, likely in utero (Courchesne et al., 2020; Gazestani et al., 2019; Grove et al., 2019). While a mechanism has not been established, atypical structural and functional brain organization is commonly observed in ASD (Holiga et al., 2019; Hull et al., 2017; Müller, 2014). The formation and maturation of connections between the thalamus and cerebral cortex (i.e., thalamocortical connections), mediated by the subplate, plays a crucial part in early cortical development (Constantinople and Bruno, 2013; Kanold and Luhmann, 2010; Kostović et al., 2011; Kostovic and Judas, 2010; O'Leary and Nakagawa, 2002). This process peaks during the third gestational trimester and when disrupted - can result in distorted topographic cortical organization with cascading consequences for postnatal sensory processing, motor learning, and cognitive development (for reviews see Hadders-Algra, 2018; Hoerder-Suabedissen and Molnár, 2015; Kanold, 2019; Luhmann et al., 2018). Genetic predisposition (Bai et al., 2019; Colvert et al., 2015; Sandin et al., 2017) and to a lesser extent environmental factors such as maternal infection during pregnancy (al-Haddad et al., 2019; Lombardo et al., 2018), prematurity, or other pregnancy or birth complications (Agrawal et al., 2018; Chien et al., 2019; Getahun et al., 2017) constitute known risk factors for ASD, and have been shown to interfere with subplate neuron function and development of thalamocortical projections (Caubit et al., 2016; Hoerder-Suabedissen et al., 2013; Hoerder-Suabedissen and Molnár, 2015; Kanold, 2003; Materna et al., 2008; McClendon et al., 2017; McQuillen et al., 2003; Mikhailova et al., 2017; Toulmin et al., 2015). Abnormal function of subplate neurons during prenatal brain development has also been detected in autism (HoerderSuabedissen et al., 2013; Hutsler and Avino, 2015; Hutsler and Casanova, 2015; Kanold, 2009; Luhmann et al., 2018; Nagode et al., 2017; Serati et al., 2019; Wess et al., 2017), and focal laminar disorganization hypothesized to result from these early developmental disruptions has been observed in the majority of children with ASD (10/11) in one post-mortem study, including in the posterior superior temporal cortices where auditory cortex is located (Stoner et al., 2014, also see Hutsler and Casanova, 2015 and McFadden and Minshew, 2013). Finally, distorted tonotopic maps 
in primary auditory cortex have been found in animal models of autism (Anomal et al., 2015; Nagode et al., 2017).

The auditory system is one of the earliest to mature in the course of brain development. Functional connectivity between thalamus and auditory cortices has been observed in neonates using in vivo fMRI (Alcauter et al., 2014; Ferradal et al., 2019), and interhemispheric functional connectivity between auditory cortices is already established in infants born prematurely and scanned before term-equivalent age (Doria et al., 2010), as well as in healthy fetuses undergoing fMRI in utero (Jakab et al., 2014; Thomason et al., 2013). Early maturation makes the auditory network vulnerable to disruption in utero or as a result of complications during birth (Barkat et al., 2011). For instance, interhemispheric auditory functional connectivity has been shown to be reduced in fetuses prior to preterm birth (Thomason et al., 2017). Rotem-Kohavi et al. (2019) observed overconnectivity within the auditory network in neonates whose mothers took selective serotonin reuptake inhibitors to treat depression during pregnancy, compared to those who did not.

Disruption to auditory cortical development likely results in atypical sound processing, with potentially cascading consequences for language and social development. In ASD, atypical cortical sound processing is evident from studies utilizing electroencephalography (EEG; Ferri et al., 2003; Hudac et al., 2018; Schwartz et al., 2018), magnetoencephalography (MEG; Yoshimura et al., 2016) and fMRI (Gomot et al., 2006; Green et al., 2019, 2017, 2015), and atypical sensitivity to sounds constitutes one of the most frequent sensory symptoms reported, affecting up to $65 \%$ of individuals with ASD (Green et al. 2015; Tharpe et al. 2006). Atypical functional connectivity between the thalamus and cortex, in particular auditory cortex, has been observed in multiple fMRI studies of children, adolescents and young adults with ASD, and has been linked to sensory as well as social deficits and repetitive behaviors (Cerliani et al., 2015; Green et al., 2017; Iidaka et al., 2019; Linke et al., 2018; Maximo and Kana, 2019; Mizuno et al., 2006; Nair et al., 2015, 2013; Woodward et al., 2017).

In addition to guiding the early development of cortical topographic organization and relaying sensory information from the periphery to primary sensory cortices, the thalamus and thalamocortical connections play an important role in regulating sleep (Anderson et al., 2005; Cueni et al., 2008; Jan et al., 2009; Steriade et al., 1993). Simultaneous fMRI-EEG studies in adults show substantial changes in functional thalamocortical connectivity during the transition to sleep (Hale et al., 2016; Mitra et al., 2017, 2015; Picchioni et al., 2014; Spoormaker et al., 2010; 
Tagliazucchi et al., 2012; Tagliazucchi and Laufs, 2014). In ASD, sleep problems are common, reported by $40-80 \%$ of individuals (Arazi et al., 2019; Carmassi et al., 2019; Krakowiak et al., 2008; Mannion and Leader, 2014; Reynolds et al., 2019; Richdale and Schreck, 2009; Sivertsen et

al., 2012), and are associated with more severe ASD symptomatology and heightened sensory sensitivity (Mazzone et al., 2018; Sikora et al., 2012; Tzischinsky et al., 2018). Together, these findings point toward disrupted thalamocortical connectivity as a possible mechanism underlying both sleep disturbances and sensory sensitivities in ASD. The current study therefore investigated thalamocortical connectivity, sleep problems, and atypical sensory processing relate in a cohort of toddlers and preschoolers with ASD.

We first aimed to examine links between sleep problems and sensory sensitivities in 15 to 65-month-old toddlers and preschoolers with ASD compared to an age-matched typically developing (TD) control group. Next, we assessed whether atypical functional connectivity (estimated from fMRI acquired during natural sleep) between the thalamus and auditory cortices could be observed in this age range, and whether it was related to sleep problems and sensory sensitivities. Given the early development of connections between the thalamus and auditory cortex, we hypothesized that functional connectivity would be increased in preschoolers with ASD and that the strength of thalamocortical functional connectivity would be related to sleep problems and sensory sensitivities. Lastly, we quantified the amplitude of low-frequency fluctuations (ALFF and fALFF, Zou et al., 2008; Zuo et al., 2010) in primary auditory cortex during resting state fMRI. Given that this index provides a measure of BOLD activity, we expected it to be increased in ASD, reflecting amplified sound processing and reduced thalamocortical gating during sleep in the noisy environment of an MRI scanner.

\section{Results}

\subsection{Sleep problems in preschoolers with ASD are associated with sensory sensitivities}

In a cohort of 70 young children with ASD and 46 typically developing (TD) children, ages 15 to 65 months, enrolled in an ongoing longitudinal study of early brain markers of autism (see Methods for inclusion criteria, and Table 1 and Table S1 for demographics), sleep problems were significantly more pronounced in children with ASD compared to TD children (Child Behavior Checklist [CBCL] Sleep Problems T score, $t(98)=-3.82, p<.001$, Figure 1A). 
Full Cohort

\begin{tabular}{|c|c|c|c|c|c|c|}
\hline & ASD & TD & & ASD & TD & \\
\hline $\mathrm{n}$ & 70 & 46 & & 29 & 30 & \\
\hline $\begin{array}{l}\text { Gestational } \\
\text { age at birth } \\
\text { (weeks) }\end{array}$ & $\begin{array}{c}38.4 \pm 2.6 \\
{[31-43]}\end{array}$ & $\begin{array}{c}39.7 \pm 1.1 \\
{[37-42]}\end{array}$ & $\begin{array}{c}t(103)=3.1 \\
p<.05\end{array}$ & $\begin{array}{c}38.5 \pm 2.5 \\
{[31-43]}\end{array}$ & $\begin{array}{c}39.5 \pm 1.2 \\
{[37-42]}\end{array}$ & $\begin{array}{c}t(54)=1.84 \\
p=.07\end{array}$ \\
\hline $\begin{array}{c}\text { Age (months) } \\
\text { at behavioral } \\
\text { assessment }\end{array}$ & $\begin{array}{c}34.7 \pm 12.4 \\
{[17-64]}\end{array}$ & $\begin{array}{c}32.6 \pm 15.2 \\
{[15-64]}\end{array}$ & $\begin{array}{c}t(114)=-.82 \\
p=.42\end{array}$ & $\begin{array}{c}33.3 \pm 9.8 \\
{[17-54]}\end{array}$ & $\begin{array}{c}34.1 \pm 14.3 \\
{[15-64]}\end{array}$ & $\begin{array}{c}t(57)=.25 \\
p=.81\end{array}$ \\
\hline $\begin{array}{l}\text { Age (months) } \\
\text { at MRI scan }\end{array}$ & $\mathrm{n} / \mathrm{a}$ & $\mathrm{n} / \mathrm{a}$ & $\mathrm{n} / \mathrm{a}$ & $\begin{array}{c}34.7 \pm 10.1 \\
{[18-56]}\end{array}$ & $\begin{array}{c}34.5 \pm 14.8 \\
{[16-65]}\end{array}$ & $\begin{array}{c}\mathrm{t}(57)=-.05 \\
p=.96\end{array}$ \\
\hline Sex (\# female) & 16 & 21 & $\begin{aligned} \chi^{2} & =6.58 \\
p & =.01\end{aligned}$ & 9 & 13 & $\begin{array}{c}\chi^{2}=.96 \\
p=.33\end{array}$ \\
\hline ADOS-2 SA & $\begin{array}{c}11.8 \pm 4.6 \\
{[3-20]}\end{array}$ & $\mathrm{n} / \mathrm{a}$ & $\mathrm{n} / \mathrm{a}$ & $\begin{array}{c}12.0 \pm 4.9 \\
{[3-19]}\end{array}$ & $\mathrm{n} / \mathrm{a}$ & $\mathrm{n} / \mathrm{a}$ \\
\hline ADOS-2 RRB & $\begin{array}{c}3.3 \pm 2.1 \\
{[0-8]}\end{array}$ & $\mathrm{n} / \mathrm{a}$ & $\mathrm{n} / \mathrm{a}$ & $\begin{array}{c}3.5 \pm 2.2 \\
{[0-8]}\end{array}$ & $\mathrm{n} / \mathrm{a}$ & $\mathrm{n} / \mathrm{a}$ \\
\hline ADOS-2 Total & $\begin{array}{c}15.0 \pm 5.5 \\
{[4-26]}\end{array}$ & $\mathrm{n} / \mathrm{a}$ & $\mathrm{n} / \mathrm{a}$ & $\begin{array}{c}15.5 \pm 5.7 \\
{[6-26]}\end{array}$ & $\mathrm{n} / \mathrm{a}$ & $\mathrm{n} / \mathrm{a}$ \\
\hline RMSD run1 & $\mathrm{n} / \mathrm{a}$ & $\mathrm{n} / \mathrm{a}$ & $\mathrm{n} / \mathrm{a}$ & $\begin{array}{c}.12 \pm .04 \\
{[.047-.188]}\end{array}$ & $\begin{array}{c}.11 \pm .04 \\
{[.046-.172]}\end{array}$ & $\begin{array}{c}t(57)=-1.04 \\
p=.30\end{array}$ \\
\hline RMSD run2 & $\mathrm{n} / \mathrm{a}$ & $\mathrm{n} / \mathrm{a}$ & $\mathrm{n} / \mathrm{a}$ & $\begin{array}{l}.12 \pm .045 \\
{[.046-.24]}\end{array}$ & $\begin{array}{l}.10 \pm .03 \\
{[.05-.176]}\end{array}$ & $\begin{array}{c}t(57)=-1.18 \\
p=.24\end{array}$ \\
\hline
\end{tabular}

Table 1. Demographics for full and fMRI cohort (reported with M (mean) \pm SD (standard deviation) and [range] when applicable). The ASD and TD groups were matched on age, sex, and in-scanner head motion (RMSD). Information on exact gestational age at birth was missing for 8 children with ASD (2/8 known to be born at term) and 3 TD children; this includes 2 ASD children (one known to be born at term) and 1 TD child in the fMRI cohort.

Since the summary CBCL Sleep Problems scale might not be an ideal measure of sleep quality (Gregory et al. 2011), we also tested for group differences in each individual item from the CBCL that assesses sleep (see Table S2). Toddlers and preschoolers with ASD were reported to have more "trouble sleeping" $\left(\chi^{2}=16.4, p<.001\right)$ and were more likely to "resist bedtime" $\left(\chi^{2}=15.3\right.$, 
$p<.001)$, to "wake up at night" $\left(\chi^{2}=11.0, p=.004\right)$, and to be "overtired" $\left(\chi^{2}=5.99, p=.05\right)$ and "sleepless" $\left(\chi^{2}=12.03, p=.001\right)$. Additionally, responses from an in-house Sleep Questionnaire (adapted for preschool age from the Brief Infant Sleep Questionnaire (BISQ), Sadeh, 2004) were assessed (Table S2). Toddlers and preschoolers with ASD were reported to take significantly longer to fall asleep (sleep latency/“time to fall asleep": ASD mean=30.3 minutes (SD=30.1), TD mean=19.7 minutes $(\mathrm{SD}=14.4), t(109)=-2.2, p=.03)$.

A)

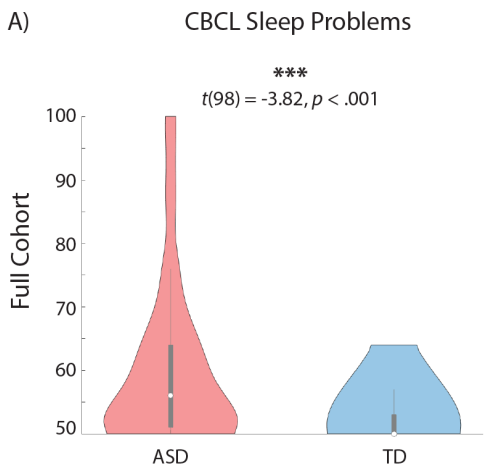

C)
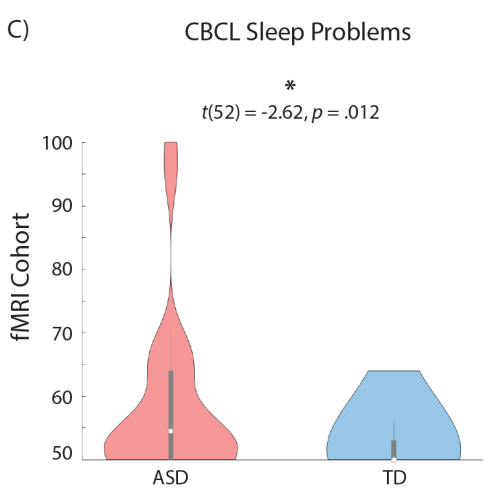
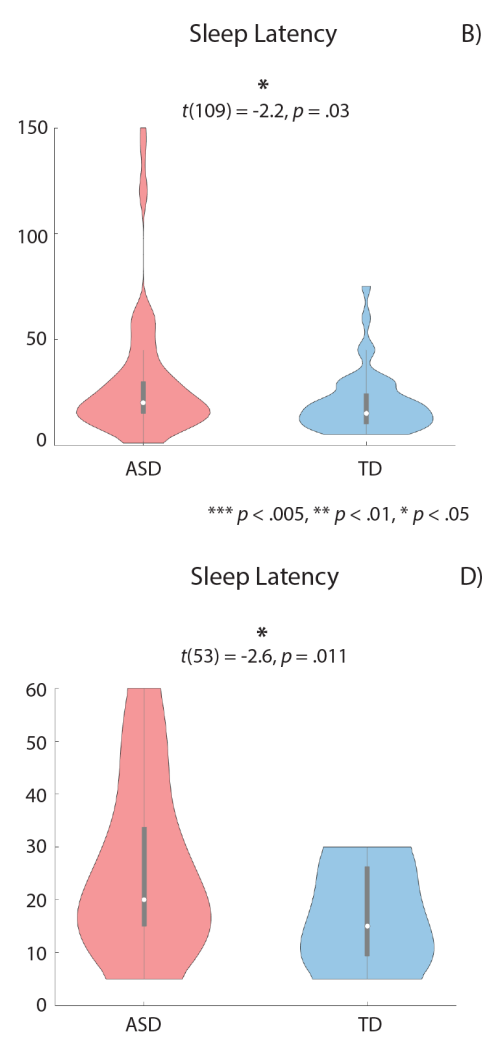

B)

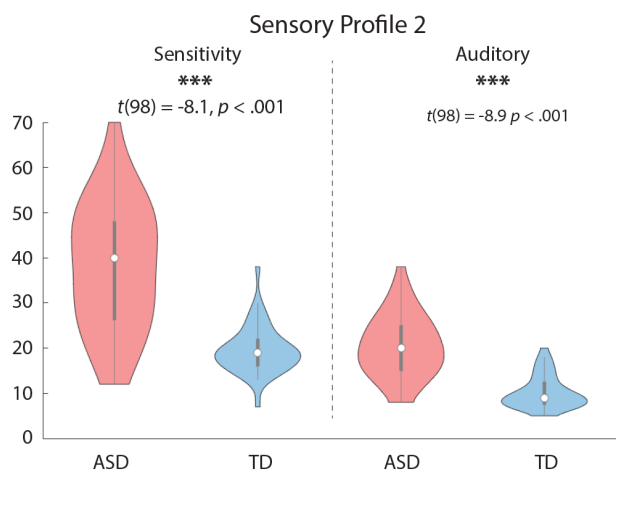

D)

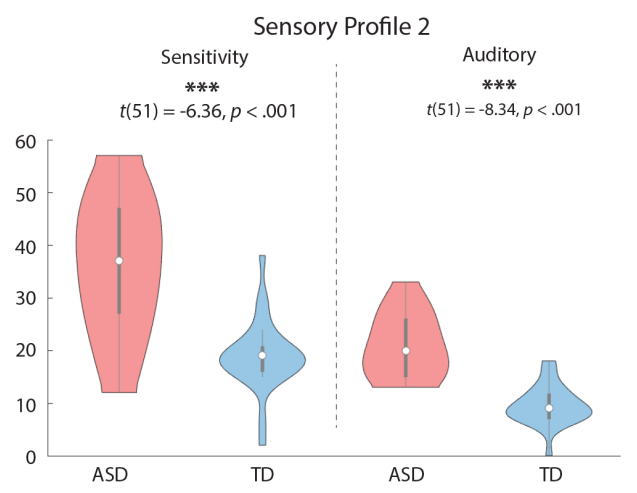

Figure 1. Greater sleep problems and sensory sensitivity, including auditory sensitivity, in toddlers and preschoolers with ASD. (A, C) More severe sleep problems (as measured using the CBCL Sleep Problems scale, T scores) and prolonged sleep latency (time, in minutes, it takes a child to fall asleep, as reported on an in-house sleep questionnaire that asked caregivers about their child's sleep habits in the past few weeks prior to participating in the study) are reported for young children with ASD compared to age and sex matched TD children, in Full Cohort (A) and the subgroup of children with successful fMRI scans (fMRI Cohort, C). (B, D) Toddlers and preschoolers with ASD show greater sensory sensitivity and more severe auditory processing symptoms as measured using the Sensory Profile 2 (T scores), in Full Cohort (B) and the subgroup of children with successful fMRI scans (fMRI Cohort, D). 
As expected, the Sensory Sensitivities score as well as the Auditory Processing score from the Toddler or Child Sensory Profile 2 (Dunn, 2014) were significantly higher in the ASD than the TD group ( $p<.001$, Figure 1B). The CBCL Sleep Problems T score positively correlated with the Sensory Profile 2 Sensory Sensitivity quadrant in the ASD group $(r=.35, p=.008$; controlling for age, Figure 2A and Table S2), with higher scores on each scale corresponding to greater impairment. The correlation with the Sensory Profile 2 Auditory Processing score was not significant $(r=.12, p=.37$; controlling for age, Table S3).

A subsample of children (see 4.1 and Table 1) successfully underwent natural sleep MRI including a high resolution structural T1-weighted image and two multiband echo-planar imaging (EPI) fMRI scans of 6-minute duration each. The ASD and TD groups with fMRI data (henceforth, fMRI cohort) did not differ on age, sex, and head-motion during the fMRI scans, and included 29 ASD and 30 TD participants. Children with successful fMRI scans did not significantly differ on any of the included Sensory Profile or CBCL sleep measures from those without MRI (neither in the ASD nor TD group, Table S4). As in the full cohort, children with ASD and successful fMRI scans had more sleep problems compared to TD peers as measured using the CBCL (Sleep Problems T score: $t(52)=-2.62, p=.012$, "trouble sleeping": $\chi^{2}=9.62, p=.008$, "resists bedtime": $\chi^{2}=9.73, p=.008$, and, marginally, "wakes up at night": $\chi^{2}=4.95, p=.08$ ). Similarly, sleep latency was prolonged in children with ASD (ASD mean=26.9 minutes ( $\mathrm{SD}=16.1$ ), TD mean=17.4 minutes $(\mathrm{SD}=10.4), t(53)=-2.6, p=.011$, Figure $1 \mathrm{C})$.

Toddlers and preschoolers with ASD in the fMRI cohort also showed greater sensory sensitivities and more severe auditory processing symptoms as assessed using the Sensory Profile 2 (both $p<.001$, Figure 1D, Table S2). Similarly, the correlation between the Sensory Profile 2 Sensory Sensitivity Quadrant score and the CBCL Sleep Problems T score was positive $(r=.39$, $p=.057$ ), consistent with the full cohort data (Figure 2B). The correlation between the Sensory Profile 2 Auditory Processing score and the CBCL Sleep Problems T score was not significant $(\mathrm{r}=.23, \mathrm{p}=.28$; partial correlations controlling for age, Table S3). 
A) Full cohort

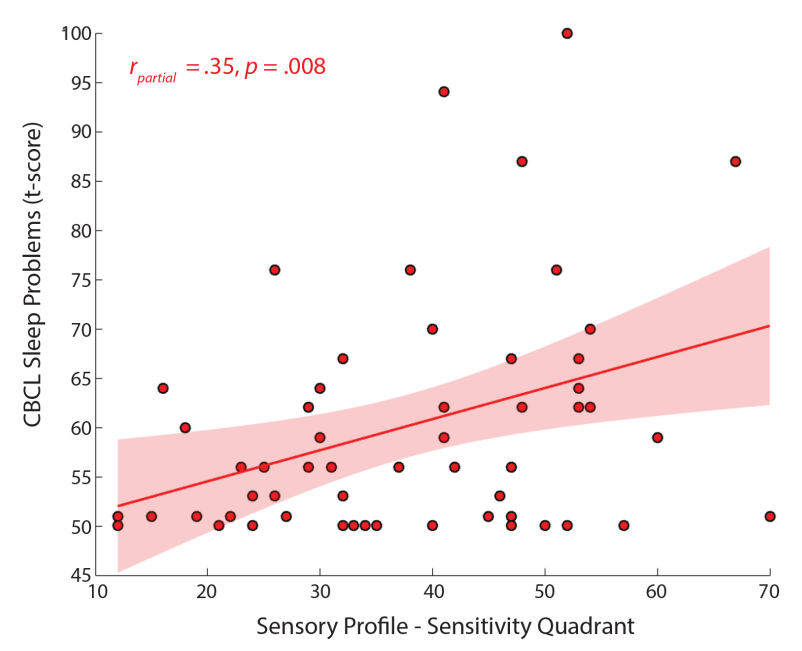

B) fMRI cohort

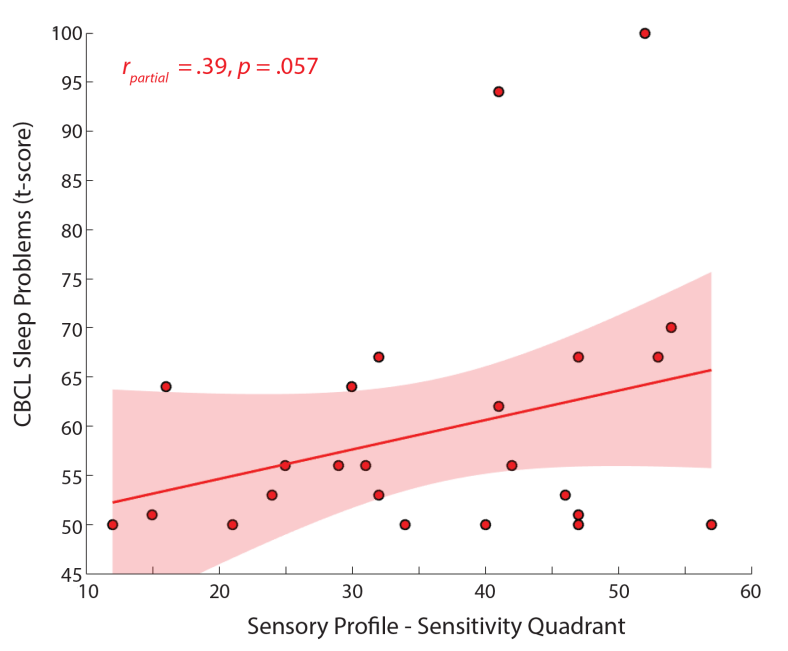

C) Relationship between sleep latency and HG-Thalamus functional connectivity
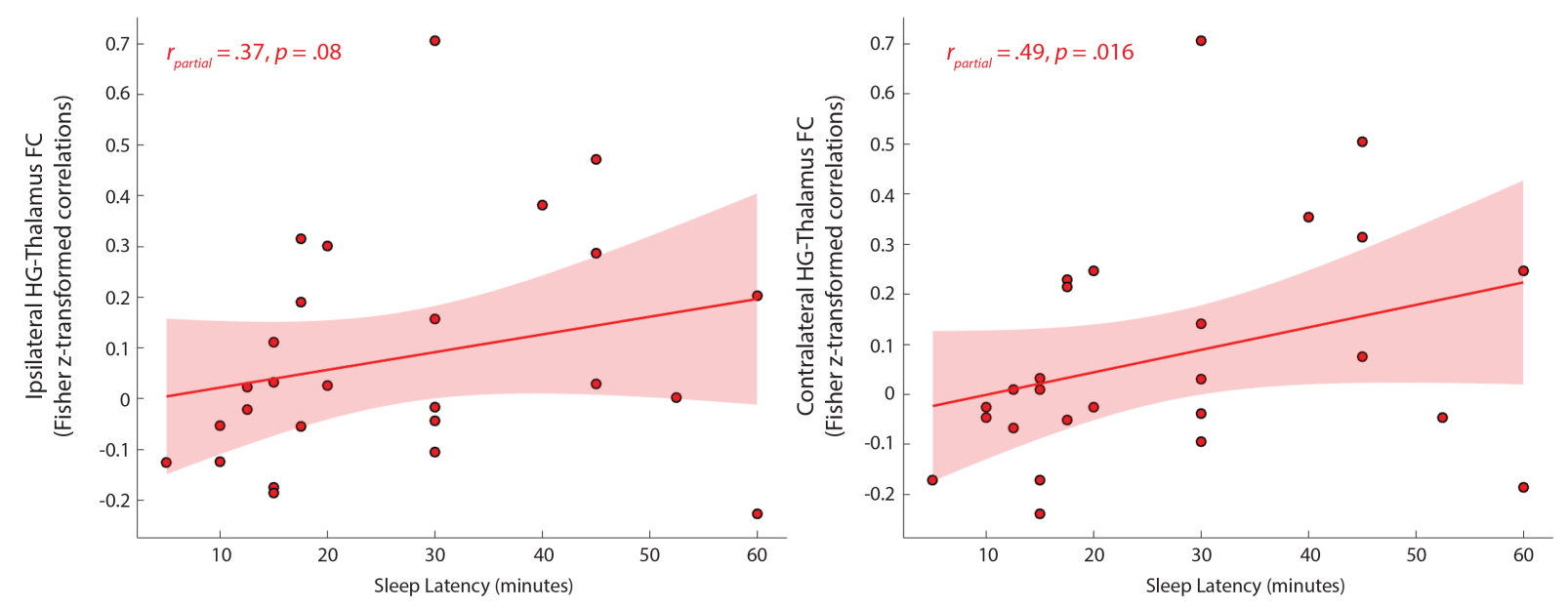

Figure 2. Correlations between sensory sensitivity, sleep problems, and HG-Thalamus FC. (A, B) The Sensory Profile Sensitivity Score correlates positively (partial correlation controlling for age) with sleep problems as quantified using the CBCL Sleep Problems T Score in the full (A) and fMRI only (B) ASD group. Correlations were not assessed for the TD group due to the narrow distribution of scores in typically developing children for these measures. (C) Sleep latency correlates positively (partial correlations controlling for in-scanner head motion [RMSD] and age) with contralateral FC between the thalamus and HG in the ASD group. Scatterplots show zeroorder correlations. 


\subsection{FC between the thalamus and HG is increased in preschoolers with ASD}

Functional connectivity analyses were carried out for left and right Heschl's Gyrus (HG) and left and right thalamus regions of interests (ROIs). FC between the thalamus and HG was significantly increased between right $\mathrm{HG}$ and right and left thalamus in the ASD compared to the TD group $(t(57)=-2.7, p=.01$ and $t(57)=-2.8, p=.007$, respectively, Figure $3 \mathrm{~A})$. FC was also higher between left $\mathrm{HG}$ and left and right thalamus in the ASD group but the group difference was not significant $(t(57)=-1.3, p=.19$ and $t(57)=-1.76, p=.08$, respectively). Ipsilateral and contralateral FC between HG and the thalamus were significantly higher in the ASD group $(t(57)=-2.5, p=.015$ and $t(57)=-$ $2.32, p=.024$, respectively). In many TD children FC estimates were close to zero or negative in line with previous reports of decreasing thalamocortical FC with anticorrelations frequently observed during deep sleep (Picchioni et al., 2014). These results remained similar when global signal regression (GSR) was included during fMRI data denoising, with FC between left HG and left and right thalamus additionally showing significant group differences after GSR (Figure S1). There was no significant correlation between functional connectivity strength and age in the ASD or TD group, or when carrying out correlations across the combined cohort for any of the auditorythalamic FC estimates (all $r<.2, p>.2$ ).

In order to assess whether overconnectivity was specific to auditory regions, seed-to-ROI analysis was carried out using the left and right thalamus as a seed and all cortical Harvard-Oxford ROIs as targets. Based on the pattern of group differences in FC (Figure 3B), results suggest overconnectivity between the thalamus and cortex is most pronounced in the temporal lobe around primary auditory cortex with right HG having the highest effect size among all comparisons for the left thalamus seed (Cohen's $d=.73$ ). Left HG similarly was among highest effect sizes for both left and right thalamus seeds (Cohen's d=.46 and d=.34, respectively).

Lastly, we assessed whether overconnectivity between thalamus and primary auditory cortex was driven by specific thalamic sub-regions. Using left and right HG as seeds, Pearson correlations were calculated for every voxel in the thalamus ROI. Results are shown in Figure 3C, with the pattern of FC suggesting that overconnectivity is strongest for the posterior regions of the thalamus, potentially overlapping with the medial geniculate nucleus, and corresponding to the functional parcellations of the thalamus derived from functional thalamocortical connectivity patterns previously, including in infants (Hwang et al., 2017; Kumar et al., 2017; Toulmin et al., 2015). 
A)

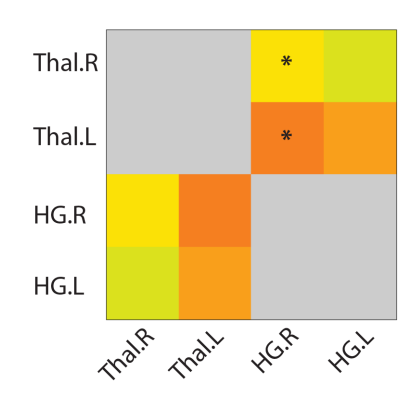

C) $\mathrm{ASD}>\mathrm{TD}$

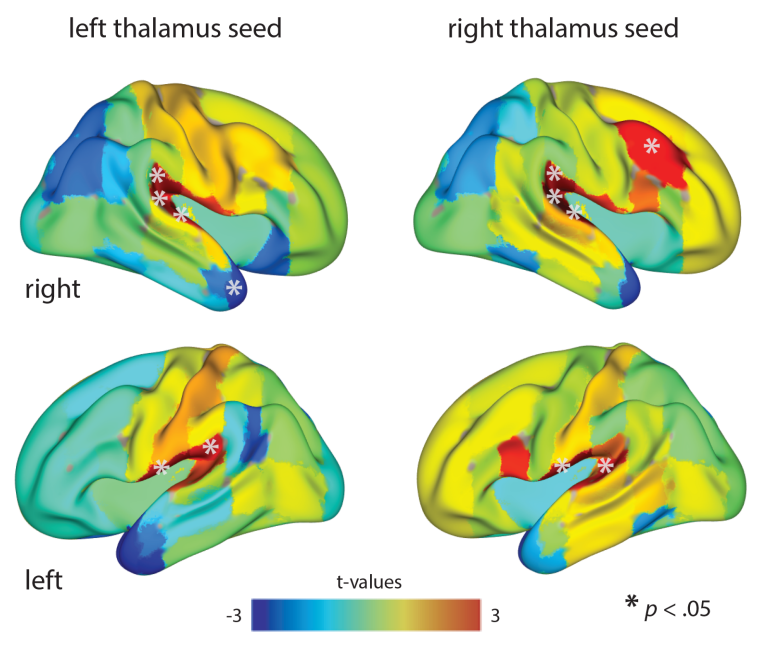

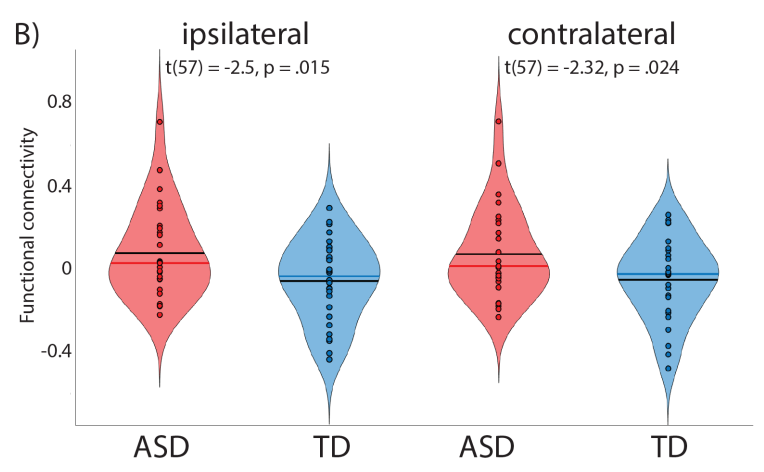

D)

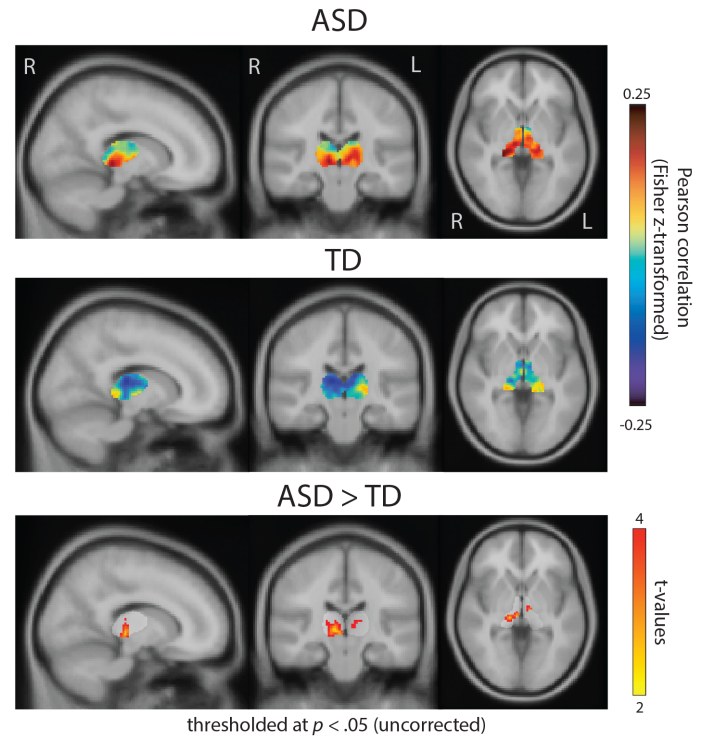

Figure 3. Thalamic-HG overconnectivity in young children with ASD. A) Toddlers and preschoolers with ASD show overconnectivity between thalamus and HG during natural sleep fMRI compared to age, motion and sex matched TD children (* in the ASD matrix mark ROI pairs with significant group differences, $p<.05$, Benjamini-Hochberg FDR-adjusted for multiple comparisons). B) Ipsilateral and contralateral FC was similarly elevated in toddlers and preschoolers with ASD and used for behavioral correlations in subsequent analyses. C) Seed-toROI analyses show that thalamocortical overconnectivity is most pronounced for auditory regions. Left and right thalami were used as seeds and all cortical Harvard-Oxford atlas ROIs as targets. tvalues for the ASD $>$ TD comparison are shown with * marking significant $(\mathrm{p}<.05$, uncorrected) group differences in FC. D) Thalamic-HG overconnectivity in the ASD group appears to be driven by the posterior section of the thalamus. Left and right HG were used as seeds and all voxels in the thalamus as targets. 


\subsection{BOLD signal amplitude is increased in auditory cortex during natural sleep in toddlers and preschoolers with ASD}

The amplitude of low frequency fluctuations (ALFF) measures the power of the BOLD signal within a low frequency range and is thought to reflect the amplitude of regional activity (Zuo et al. 2008; Zuo et al. 2010). ALFF $(t(57)=2.4, p=.02$, ) and fALFF $(t(57)=1.9, p=.06)$ were higher in HG in the ASD compared to the TD group (Figure S3). Neither ALFF nor fALFF correlated significantly with Sensory Profile Sensory Sensitivity or Auditory Processing Scores or with the CBCL Sleep Problems T-score in children with ASD.

\section{Discussion}

We investigated the relationship between auditory thalamocortical FC, sleep problems, and sensory sensitivities in toddlers and preschoolers with ASD. Elevated sleep problems and sensory sensitivities, as reported by caregivers, were positively correlated in children with ASD, and increased sleep latency was associated with higher thalamocortical connectivity during natural sleep. Our findings support a model of both atypical sensory processing and sleep problems being linked to early neurodevelopmental disturbances of thalamocortical connectivity.

\subsection{Atypical thalamocortical FC may underlie both sensory sensitivities and sleep problems in young children with ASD}

Sensory over-responsivity can interfere with sleep (Cortesi et al., 2010; Reynolds and Malow, 2011), accounting for correlations reported between sleep problems and sensory sensitivities in ASD (Tzischinsky et al., 2018). The mechanisms behind sensory sensitivities and sleep problems however remain unclear. In this study, we focused specifically on investigating FC between the thalamus and auditory cortex and its association with sleep problems and sensory sensitivities for a number of reasons: 1) connections between the thalamus and auditory cortex are established early in development (Alcauter et al., 2014; Ferradal et al., 2019) making them particularly vulnerable to disruption in utero (Barkat et al., 2011); 2) the formation of tonotopic maps in auditory cortex is guided by thalamocortical connections in utero and its disruption can result in atypical sound processing, as has been shown in animal models of ASD (Anomal et al., 2015; Nagode et al., 2017); 3) altered sensitivity to, and atypical cortical processing of sounds is very common in ASD and has been linked to reduced modulation of thalamocortical FC (Green et al., 
2017); and 4) a relationship between atypical sensory gating by the thalamus during sleep as reflected by increased thalamocortical connectivity and elevated BOLD amplitude was likely to be most obvious in auditory cortex given sleep fMRI is collected in the presence of substantial noise produced by the MRI scanner.

Similar to findings in older children and adolescents with ASD who underwent resting state fMRI while awake (Linke et al. 2018; Nair et al. 2015; Woodward et al. 2017), auditory-thalamic FC was elevated in toddlers and preschoolers with ASD scanned during natural sleep in the current study. While auditory-thalamic FC was positively associated with sleep problems, particularly the time it takes children to fall asleep, it did not correlate with sensory sensitivities. The Sensory Profile may not have quantified atypical auditory processing in ASD with high reliability (Schulz and Stevenson, 2019), as it relies on caregiver report and some questions targeting modalityspecific processing also tap into non-sensory aspects of behavior. Previous studies employing sensory stimulation fMRI designs (e.g. Green et al. 2017) have found thalamocortical overconnectivity in ASD to be associated with sensory over-responsivity (quantified as a composite score derived from the Short Sensory Profile (Dunn, 1999) and Sensory OverResponsivity (SensOR) Inventory (Schoen et al., 2008)). The lack of a relationship between sensory sensitivities as broadly assessed with the Sensory Profile and auditory thalamocortical FC is thus likely to reflect the Sensory Profile psychometric limitations.

\subsection{Evidence for early development of atypical auditory-thalamocortical FC}

Auditory-thalamic FC did not correlate with age, suggesting that the observed overconnectivity reflects early neurodevelopmental disruptions preceding toddler age. Postmortem histology and studies in autism animal models provide evidence for altered establishment of thalamocortical projections and topographic sensory maps in utero potentially as a result of atypical subplate function (Barkat et al., 2011; Constantin et al., 2020; HoerderSuabedissen et al., 2013; Hutsler and Casanova, 2015; Kanold et al., 2019; McFadden and Minshew, 2013; Molnár et al., 2020; Nagode et al., 2017; Serati et al., 2019). Recent findings from an infant sibling fMRI study support this interpretation, showing increased FC between the thalamus and somatosensory cortex in six-week old infants at high familial risk of ASD (Nair et al., preprint: https:/www.biorxiv.org/content/10.1101/2020.06.07.139147v1), which was associated with increased ASD symptoms at 36 months. Relatedly, in a large group of at-risk infant 
siblings, Swanson et al. (2017) reported that thalamus volumes at 12 months differentially predicted language skills at 24 months in those with ASD compared to those with language delay or without familial risk. Abnormalities in auditory cortical processing (Kolesnik et al., 2019) as well as increased prevalence of sleep problems (Humphreys et al., 2014; Nguyen et al., 2018) tied to differences in brain development (MacDuffie et al., 2020) have also been observed in infant sibling studies of ASD, further strengthening the notion that underlying neurodevelopmental disruptions occur very early.

\subsection{Possible mechanisms: Atypical modulation of thalamocortical FC during awake and sleep states and reduced sensory gating}

Unlike in older children and adults scanned awake, average FC between auditory cortex and the thalamus was close to zero or negative in TD toddlers and preschoolers in our study, with overconnectivity in the ASD group driven by a positive shift in correlation magnitudes. Functional connectivity between cortex and subcortical structures changes substantially during sleep, with a reduction in thalamocortical connectivity observed in fMRI studies conducted during deep sleep in adults (Picchioni et al. 2014). Mitra et al. (2017) scanned asleep young children (from 6 to 24 months) and compared the lag pattern of FC to that of adults scanned awake and asleep. During N3 sleep, the BOLD responses of the thalamus and cortex showed increased lag compared to wakefulness, in both sleeping 2-year-olds and sleeping adults. While the authors did not report zero-lag FC of the thalamus, increased lag of thalamic BOLD timeseries during N3 sleep is likely to result in negative or reduced thalamocortical FC compared to wakefulness. Increased FC in the ASD group observed in the current study may therefore reflect a lack of thalamocortical modulation during sleep. It is not possible to discern from the current study whether those children with increased thalamocortical connectivity during deep sleep would also show heightened thalamocortical connectivity while awake. However, findings from previous studies show that thalamocortical overconnectivity in ASD is also present in the awake state. Similarly, in schizophrenia, thalamocortical overconnectivity during awake state has been observed in multiple studies (Chen et al., 2019; Skåtun et al., 2018; Woodward et al., 2012), and is associated with reduced sleep spindle density (Baran et al., 2019). Baran et al. conclude that reduced inhibition by the thalamic reticular nucleus results in both reduced sensory gating (reflected by increased thalamocortical FC) and sleep spindle deficits. Reduced sleep spindle density and duration has 
also been observed in 2 to 6-year-old children with ASD (Farmer et al., 2018). During wakefulness, children with ASD not only show thalamocortical overconnectivity but also less modulation of thalamocortical connectivity in response to sensory stimulation (Green et al., 2017) and less habituation of auditory cortical processing when presented with aversive auditory stimuli (Green et al., 2019). Additionally, in healthy adults, activity in auditory cortex decreases during sleep (Czisch et al., 2002). In our study, ALFF - a measure of the amplitude of BOLD fluctuations - in HG was significantly higher during sleep in toddlers and preschoolers with ASD, potentially reflecting heightened ongoing sound processing in the auditory cortex or a lack of habituation to the scanner noise. In combination with the previous literature and increased auditory-thalamic FC, these findings support an explanation of reduced sensory gating during sleep in ASD. Atypical modulation of thalamocortical functional connectivity during awake and sleep states might thus offer an explanation for both sensory sensitivities and sleep problems in ASD.

In the absence of simultaneous EEG recordings - which cannot be obtained in sleeping toddlers or preschoolers during fMRI without risking substantial data loss - exact sleep stage is difficult to objectively determine in natural sleep fMRI studies. Note that obtaining MRI data with sufficient data quality in sleeping toddlers and preschoolers is practically impossible unless a child is in deep, motionless sleep. We nevertheless conducted a number of additional analyses suggesting that auditory-thalamic overconnectivity in preschoolers with ASD was not driven by differences in sleep stage (see Supplementary Material and Figure S4). These additional analyses, however, cannot rule out other qualitative differences in sleep. This is supported by a number of EEG studies showing atypical sleep architecture in young children with ASD (e.g. Arazi et al., 2019; Farmer et al., 2018; Lehoux et al., 2019; Page et al., 2020). Particularly, atypical slow wave activity (Arazi et al. 2019; Lehoux et al. 2019) and reduced sleep spindle generation (Farmer et al. 2018) as observed with EEG in young children with ASD has been associated with altered thalamocortical FC during deep sleep (Baran et al. 2019). This is, however, fully consistent with our conclusion of sleep problems in ASD being associated with atypical auditory-thalamic FC and sensory sensitivities. Given the consequences that disrupted sensory processing and sleep might have on development, understanding the relationship between mechanisms underlying sleep problems and the emergence of core ASD symptomatology early in life is of crucial importance. Our findings suggest that early developmental abnormalities of thalamocortical connectivity in 
ASD are linked to both sleep disturbances and sensory problems, laying out a pathway for mechanistic models and ultimately targeted neurobehavioral interventions.

\section{Methods}

\subsection{Participants}

70 young children with ASD and 46 typically developing (TD) children, ages 15 to 65 months, were enrolled in an ongoing longitudinal study of early brain markers of autism. Children with a (suspected) diagnosis of autism were referred from specialty autism clinics, state-funded early education and developmental evaluation programs, local pediatricians, service providers, and community clinics; TD children were recruited from the community. Participants were excluded for comorbid ASD-related medical or genetic conditions (e.g., epilepsy, fragile X or Rett syndrome, tuberous sclerosis), or other neurological conditions (e.g., cerebral palsy, Tourette syndrome). Participants in the TD group were also excluded for premature birth $(<36$ weeks gestational age at birth), and personal or family history (first degree relatives) of ASD, intellectual disability, or other heritable psychiatric or neurological disorders.

All participants were safety-screened for MRI contraindications (e.g., ferrous material in body). Consent was acquired from caregivers, and families were compensated for their time. The research protocol was approved by the institutional review boards of the University of California San Diego and San Diego State University. MRI data were acquired during natural sleep (see SI) from 76/116 children (42 ASD, 34 TD). MRI data were missing in 40 children, as a result of inability to fall or stay asleep in the scanner (29 participants: 21 ASD, 8 TD) or because they did not return for their MRI appointment (11 participants: 7 ASD, 4 TD). 17 MRI datasets were further excluded from analyses due to excessive motion or missing one of the two fMRI runs ( $\mathrm{n}=13 \mathrm{ASD}$, $n=1$ TD) or to achieve age and sex matching ( $n=3$ TD) between the ASD and TD groups. The final ASD and TD groups with $\mathrm{fMRI}$ data did not differ on age, sex, and head-motion during the fMRI scans, and included 29 ASD and 30 TD participants. Demographics for all participants included in behavioral (full cohort) and fMRI (fMRI cohort) analyses are summarized in Table 1 and Table $\mathrm{S} 1$. 


\subsection{Diagnostic and Behavioral Assessments}

All participants in the ASD group received a diagnosis of ASD (or clinical best estimate in children younger than age 3 years, Ozonoff et al., 2015) based on the DSM-5 criteria (American Psychiatric Association, 2013), supported by the Autism Diagnostic Observation Schedule, Second Edition (ADOS-2, Lord et al., 2012, Table 1), administered by research-reliable clinicians, the Autism Diagnostic Interview-Revised (ADI-R, for children older than 36 months), and expert clinical judgment. Parents also completed the Social Communication Questionnaire (SCQ, Current form, Lord and Rutter, 2003), a screener for autism spectrum disorders, with no TD participants exceeding the cut-off score of 15 (all TD scores $\leq 10$ ). Measures summarizing sleep problems were obtained from the Preschool Child Behavior Checklist (CBCL) and from an in-house Sleep Questionnaire (adapted for toddlers and preschoolers from the Brief Infant Sleep Questionnaire (BISQ), Sadeh, 2004). The CBCL Sleep Problems T score, the six individual items it is derived from (Gregory et al., 2011) and 7 items from the Sleep Questionnaire were included in analyses (see SI for details on CBCL sleep items). To quantify sensory symptoms and in particular sound sensitivities, the Toddler or Child Sensory Profile 2 (Dunn, 2014) was administered to caregivers, and the "sensitivity" quadrant score and auditory processing score were used in analyses (with greater scores corresponding to greater impairment).

ASD and TD group differences in the CBCL Sleep Problems T score, individual CBCL sleep items (see SI), the Sleep Questionnaire items, and the Sensory Profile scores were tested using independent samples two-tailed t-tests or likelihood ratio chi square tests for the full cohort and separately for the subgroup of children with fMRI data. Given the restricted range of scores in the TD group, Pearson correlations were carried out to test for a relationship between sensory sensitivities (Sensory Profile Sensitivity quadrant and Auditory Processing score) and sleep problems (CBCL Sleep Problems T score) in the ASD group only.

\subsection{Magnetic Resonance Imaging Data Acquisition}

In preparation for the scan night, and to optimize MRI data acquisition, a comprehensive habituation protocol was implemented. After an individualized scan night sleep strategy (e.g., time of arrival, approximating home-like sleeping arrangements, including access to a double MRI bed for co-sleeping families, lighting in the MRI suite, etc.) was developed for each child, based on 
the typical bedtime routines and habits assessed in advance, families were instructed to practice inserting soft foam child-size earplugs and to play recordings of the MRI sequences employed in the study for at least a week prior to the scan. During the MRI session, children wore earplugs ( $\sim 30 \mathrm{~dB}$ sound attenuation), and MRI-compatible headphones (MR Confon) were used to play white noise at a comfortable listening level to keep the noise level constant and prevent children from waking up during scan transitions. A weighted blanket kept children comfortable and reduced motion, and a caregiver and/or member of the research team remained in the scanner room throughout the session to monitor sleep, motion, and comfort.

Natural sleep MRI data were collected at the University of California San Diego Center for Functional MRI on a GE 3T Discovery MR750 scanner using a Nova Medical 32-channel head coil. A multiband EPI sequence allowing simultaneous acquisition of multiple slices was used to acquire two fMRI datasets (6-minute duration each) with high spatial and temporal resolution $\left(\mathrm{TR}=800 \mathrm{~ms}, \mathrm{TE}=35 \mathrm{~ms}\right.$, flip angle $52^{\circ}, 72$ slices, multiband acceleration factor $8,2 \mathrm{~mm}$ isotropic voxel size, 104x104 matrix size, FOV $20.8 \mathrm{~cm}, 400$ volumes per run). Two separate 20s spin-echo EPI sequences with opposing phase encoding directions were also acquired using the same matrix size, FOV and prescription to correct for susceptibility-induced distortions. After completion of the fMRI scans, a fast 3D spoiled gradient recalled (FSPGR) T1-weighted sequence was used to acquire high-resolution structural images $(0.8 \mathrm{~mm}$ isotropic voxel size, $\mathrm{NEX}=1$, TE/TI=min full $/ 1060 \mathrm{~ms}$, flip angle $8^{\circ}, \mathrm{FOV}=25.6 \mathrm{~cm}$, matrix $=320 \times 320$, receiver bandwidth $31.25 \mathrm{hz}$ ). Motion during structural acquisitions was corrected in real-time using three navigator scans (PROMO, real-time prospective motion correction White et al., 2010), and images were bias corrected using the GE PURE option.

\subsection{Imaging data preprocessing and denoising}

MRI data were preprocessed, denoised and analyzed in Matlab $2015 \mathrm{~b}$ (Mathworks Inc., Natick, MA, USA) using SPM12 (Wellcome Trust Centre for Neuroimaging, University College London, UK), and the CONN toolbox v17f (Whitfield-Gabrieli \& Nieto-Castanon, 2012).

The structural images were converted from dicom to nifti format and were coregistered to the mean functional images, segmented and normalized to MNI space using non-linear registration and the default tissue probability maps included with SPM12. The white matter (WM) probability 
maps obtained from segmentation of the structural image for each individual subject were thresholded at 0.95 and eroded by 1 voxel. WM and CSF time courses were extracted from the thresholded and eroded masks using aCompCor (Behzadi et al., 2007) for subsequent nuisance regression (see below).

Functional images were corrected for susceptibility-induced distortions using the two spinecho EPI acquisitions with opposite phase encoding directions and FSL's TOPUP tools (Smith et al., 2004). Subsequently, functional images were motion-corrected using rigid-body realignment as implemented in SPM12. The Artifact Detection Toolbox (ART, as installed with CONN v17f) was used to identify outliers in the functional image time series from the resulting 6 motion parameters ( 3 translational and 3 rotational) that had frame-wise displacement (FD) $>0.5 \mathrm{~mm}$ and/or changes in signal intensity that were greater than three standard deviations. As oscillations due to respiration are prominent in motion parameters derived from multiband EPI realignment (Fair et al. 2018) and would result in unnecessary censoring of large chunks of data in some participants, the thresholds to detect outliers were more lenient than those used for standard resting state fMRI acquisitions with slower TRs. In order to ensure that none of our findings were due to differences in apparent motion between groups, groups were matched on RMSD calculated from rigid-body realignment of the raw data prior to TOPUP correction (Table 1).

Functional images were directly normalized to MNI space with the same non-linear registration as used for the structural images. The MNI template rather than an age-appropriate template was used for normalization due to the wide age range and cross-sectional analyses conducted. Data were visually inspected for quality by two members of the research team (authors $\mathrm{AL}$ and $\mathrm{BC}$ ) independently, at each pre-processing step, including determining successful normalization. Voxel timeseries were converted to percent-signal change separately for each EPI acquisition. Since all analyses were run on averaged voxel time series within pre-defined ROIs, no prior smoothing was applied to the data. Band-pass filtering using a temporal filter of 0.008 to 0.08 Hz was carried out as part of the nuisance regression ("simult" option in the CONN toolbox) which also included scrubbing of the motion outliers detected by the ART toolbox, and regression of the 6 motion parameters and their derivatives, as well as the first five PCA component time series derived from the CSF and white matter masks. The residuals of the nuisance regression were then used for all subsequent analyses. Analyses were repeated including the global signal, calculated as the average timeseries of all voxels in the brain, as a nuisance regressor (see Figure S1). 


\subsection{Functional MRI Analyses}

\subsubsection{Regions of interest}

Analyses were carried out within left and right Heschl's Gyrus (HG) and left and right thalamus regions of interests (ROIs) extracted from the Harvard-Oxford atlas provided by FSL and the CONN toolbox. Additional functional connectivity analyses included all cortical Harvard-Oxford atlas ROIs to determine whether atypical thalamocortical connectivity was specific to auditory cortices (see below).

\subsubsection{Functional connectivity analysis}

BOLD time series were concatenated across the two EPI acquisitions and averaged across all voxels within each ROI. First, functional connectivity (FC) between bilateral thalamus and HG was estimated using bivariate Pearson correlation standardized with a Fisher z-transform. Twotailed independent samples t-tests were used to assess differences in correlation magnitude between pairs of ROIs in the ASD compared to the TD group. Separate tests were also carried out for ipsilateral (average of intrahemispheric thalamus-HG FC) and contralateral (average of interhemispheric thalamus-HG) FC. Functional connectivity (Fisher z) was Pearson correlated with age, separately in each group, to test for any age-related changes in auditory thalamocortical connectivity. We hypothesized that auditory-thalamic FC would be elevated in toddlers and preschoolers with ASD. Results are reported at a threshold of $\mathrm{p}<.05$ (Benjamini-Hochberg FDR adjusted for multiple comparisons). To assess whether atypical thalamocortical connectivity was specific to sensory regions of the brain, a post-hoc analysis also assessed whole brain thalamocortical connectivity using the left and right thalamus as seeds and all Harvard-Oxford cortical ROIs as targets. Independent samples t-tests of the Fisher-z-transformed estimates of FC assessed differences between the ASD and TD groups. Lastly, we assessed in an exploratory analysis whether atypical functional connectivity between $\mathrm{HG}$ and the thalamus was driven more strongly by specific regions within the thalamus, involved in auditory processing (Hwang et al., 2017; Kumar et al., 2017; Toulmin et al., 2015). BOLD timeseries within left and right HG were Pearson correlated with the timeseries of every voxel within the thalamus ROIs, and t-tests carried out for the Fisher-z-transformed correlation coefficient of each thalamic voxel to test for ASD-TD differences. To rule out that children in the ASD and TD group might have been scanned during 
different sleep stages, which could confound functional connectivity estimates, a number of additional analyses were conducted and are described in the Supplementary Information.

\subsubsection{Fractional amplitude of low frequency fluctuations}

The amplitude of low frequency fluctuations (ALFF) measures the power of the BOLD signal within a low frequency range and is thought to reflect the amplitude of regional neural activity. ALFF was calculated as:

$$
A L F F=\sqrt{\frac{1}{N} \sum_{t}\left(h(t) * B O L D(x, t)^{2}\right.}
$$

as implemented in the CONN toolbox, with $\mathrm{N}=$ the number of volumes, $\operatorname{BOLD}(\mathrm{x}, \mathrm{t})=$ original BOLD timeseries before bandpass filtering, and $\mathrm{h}(\mathrm{t})=$ bandpass filter (see https://web.conntoolbox.org/measures/other for more detail). The fractional amplitude of low frequency fluctuations (fALFF) was developed to better protect against noise and is a measure of the relative contribution of low frequency fluctuations to the entire frequency range detectable by BOLDoptimized EPI (Zou et al., 2008; Zuo et al., 2010). It was calculated as the power within the low frequency range $(0.01-0.1 \mathrm{~Hz})$ divided by the total power of the entire frequency spectrum, again using the implementation included with the CONN toolbox:

$$
f A L F F=\sqrt{\frac{\sum_{t}(h(t) * B O L D(x, t))^{2}}{\sum_{t} B O L D(x, t)^{2}}}
$$

ALFF and fALFF were calculated for each voxel in the brain and extracted and averaged for the left and right HG ROIs. We hypothesized that ALFF and fALFF would be increased in HG in the ASD group, which was tested using independent samples two-tailed t-tests.

\subsection{Relationship between FC, sleep problems and sensory sensitivities}

Partial correlations (correcting for average head motion [RMSD] and age) tested for a relationship between HG-thalamus FC and sensory sensitivities (Sensory Profile Sensitivity Quadrant and Auditory Processing score), the CBCL Sleep Problems T score, and those Sleep Questionnaire items that showed significant ASD-TD group differences in the fMRI cohort. To reduce the number of multiple comparisons, correlations were only conducted for contralateral and ipsilateral 
FC. Due to the narrow distribution of CBCL and Sensory Profile scores in the TD group, correlations where only assessed for children with ASD. We hypothesized that elevated FC between the thalamus and HG would be related to greater sensory sensitivity and more severe sleep problems in the ASD group. Given relatively small sample size for detecting robust brain-behavior relationships, these results are presented as preliminary and uncorrected for multiple comparisons and need to be interpreted with caution.

\section{Data Availability}

The data that support the findings presented in this manuscript will be available in the NIMH Data Archive (NDA), an NIH-funded data repository (https://nda.nih.gov/). Software used for all analyses are available to researchers for replication.

\section{Acknowledgments}

We thank Lisa Mash, M.S. (San Diego State University) and Tiffany Wang, M.S. (University of California, San Diego) for invaluable assistance with data collection. Our strongest gratitude goes to the children and families who so generously dedicated their time and effort to this research.

\section{Funding}

This research was supported by the National Institutes of Health (R01 MH107802 to I.F.).

\section{Competing Interests}

Nothing to report. 


\section{References}

Agrawal, S., Rao, S.C., Bulsara, M.K., Patole, S.K., 2018. Prevalence of Autism Spectrum Disorder in Preterm Infants: A Meta-analysis. Pediatrics 142, e20180134. doi:10.1542/PEDS.2018-0134

al-Haddad, B.J.S., Jacobsson, B., Chabra, S., Modzelewska, D., Olson, E.M., Bernier, R., Enquobahrie, D.A., Hagberg, H., Östling, S., Rajagopal, L., Adams Waldorf, K.M., Sengpiel, V., 2019. Long-term Risk of Neuropsychiatric Disease After Exposure to Infection In Utero. JAMA Psychiatry 76, 594. doi:10.1001/jamapsychiatry.2019.0029

Alcauter, S., Lin, W., Smith, J.K., Short, S.J., Goldman, B.D., Reznick, J.S., Gilmore, J.H., Gao, W., 2014. Development of Thalamocortical Connectivity during Infancy and Its Cognitive Correlations. J. Neurosci. 34, 9067-75. doi:10.1523/JNEUROSCI.0796-14.2014

Anderson, M.P., Mochizuki, T., Xie, J., Fischler, W., Manger, J.P., Talley, E.M., Scammell, T.E., Tonegawa, S., 2005. Thalamic Cav3.1 T-type Ca2+ channel plays a crucial role in stabilizing sleep. Proc. Natl. Acad. Sci. U. S. A. 102, 1743-8.

doi:10.1073/pnas.0409644102

Anomal, R.F., de Villers-Sidani, E., Brandão, J.A., Diniz, R., Costa, M.R., Romcy-Pereira, R.N., 2015. Impaired Processing in the Primary Auditory Cortex of an Animal Model of Autism.

Front. Syst. Neurosci. 9, 158. doi:10.3389/fnsys.2015.00158

Arazi, A., Meiri, G., Danan, D., Michaelovski, A., Flusser, H., Menashe, I., Tarasiuk, A., Dinstein, I., 2019. Reduced sleep pressure in young children with autism. Sleep. doi:10.1101/706135

Bai, D., Yip, B.H.K., Windham, G.C., Sourander, A., Francis, R., Yoffe, R., Glasson, E., Mahjani, B., Suominen, A., Leonard, H., Gissler, M., Buxbaum, J.D., Wong, K., Schendel, D., Kodesh, A., Breshnahan, M., Levine, S.Z., Parner, E.T., Hansen, S.N., Hultman, C., Reichenberg, A., Sandin, S., 2019. Association of Genetic and Environmental Factors With Autism in a 5-Country Cohort. JAMA Psychiatry. doi:10.1001/jamapsychiatry.2019.1411

Baran, B., Karahanoğlu, F.I., Mylonas, D., Demanuele, C., Vangel, M., Stickgold, R., Anticevic, A., Manoach, D.S., 2019. Increased Thalamocortical Connectivity in Schizophrenia Correlates With Sleep Spindle Deficits: Evidence for a Common Pathophysiology. Biol. Psychiatry Cogn. Neurosci. Neuroimaging 4, 706-714. doi:10.1016/j.bpsc.2019.04.012

Barkat, T.R., Polley, D.B., Hensch, T.K., 2011. A critical period for auditory thalamocortical connectivity. Nat. Neurosci. 14, 1189-1194. doi:10.1038/nn.2882

Behzadi, Y., Restom, K., Liau, J., Liu, T.T., 2007. A component based noise correction method (CompCor) for BOLD and perfusion based fMRI. Neuroimage 37, 90-101. doi:10.1016/j.neuroimage.2007.04.042

Carmassi, C., Palagini, L., Caruso, D., Masci, I., Nobili, L., Vita, A., Dell’Osso, L., 2019. Systematic Review of Sleep Disturbances and Circadian Sleep Desynchronization in Autism Spectrum Disorder: Toward an Integrative Model of a Self-Reinforcing Loop. Front. Psychiatry 10, 366. doi:10.3389/fpsyt.2019.00366

Caubit, X., Gubellini, P., Andrieux, J., Roubertoux, P.L., Metwaly, M., Jacq, B., Fatmi, A., HadAissouni, L., Kwan, K.Y., Salin, P., Carlier, M., Liedén, A., Rudd, E., Shinawi, M., Vincent-Delorme, C., Cuisset, J.-M., Lemaitre, M.-P., Abderrehamane, F., Duban, B., Lemaitre, J.-F., Woolf, A.S., Bockenhauer, D., Severac, D., Dubois, E., Zhu, Y., Sestan, N., Garratt, A.N., Lydia Kerkerian-Le, G., Fasano, L., 2016. TSHZ3 deletion causes an autism syndrome and defects in cortical projection neurons. Nat. Genet. 48, 1359-1369. doi:10.1038/ng.3681 
Cerliani, L., Mennes, M., Thomas, R.M., Di Martino, A., Thioux, M., Keysers, C., 2015. Increased Functional Connectivity Between Subcortical and Cortical Resting-State Networks in Autism Spectrum Disorder. JAMA Psychiatry. doi:10.1001/jamapsychiatry.2015.0101

Chen, P., Ye, E., Jin, X., Zhu, Y., Wang, L., 2019. Association between Thalamocortical Functional Connectivity Abnormalities and Cognitive Deficits in Schizophrenia. Sci. Rep. 9, 1-10. doi:10.1038/s41598-019-39367-z

Chien, Y.-L., Chou, M.-C., Chou, W.-J., Wu, Y.-Y., Tsai, W.-C., Chiu, Y.-N., Gau, S.S.-F., 2019. Prenatal and perinatal risk factors and the clinical implications on autism spectrum disorder. Autism 23, 783-791. doi:10.1177/1362361318772813

Colvert, E., Tick, B., McEwen, F., Stewart, C., Curran, S.R., Woodhouse, E., Gillan, N., Hallett, V., Lietz, S., Garnett, T., Ronald, A., Plomin, R., Rijsdijk, F., Happé, F., Bolton, P., 2015. Heritability of Autism Spectrum Disorder in a UK Population-Based Twin Sample. JAMA Psychiatry 72, 415. doi:10.1001/jamapsychiatry.2014.3028

Constantin, L., Poulsen, R.E., Scholz, L.A., Favre-Bulle, I.A., Taylor, M.A., Sun, B., Goodhill, G.J., Vanwalleghem, G.C., Scott, E.K., 2020. Altered brain-wide auditory networks in a zebrafish model of fragile X syndrome. BMC Biol. 18, 125. doi:10.1186/s12915-02000857-6

Constantinople, C.M., Bruno, R.M., 2013. Deep Cortical Layers Are Activated Directly by Thalamus. Science (80-. ). 340, 1591-1594. doi:10.1126/science.1236425

Cortesi, F., Giannotti, F., Ivanenko, A., Johnson, K., 2010. Sleep in children with autistic spectrum disorder. Sleep Med. 11, 659-664. doi:10.1016/j.sleep.2010.01.010

Courchesne, E., Gazestani, V.H., Lewis, N.E., 2020. Prenatal Origins of ASD: The When, What, and How of ASD Development. Trends Neurosci. doi:10.1016/j.tins.2020.03.005

Cueni, L., Canepari, M., Luján, R., Emmenegger, Y., Watanabe, M., Bond, C.T., Franken, P., Adelman, J.P., Lüthi, A., 2008. T-type Ca2+ channels, SK2 channels and SERCAs gate sleep-related oscillations in thalamic dendrites. Nat. Neurosci. 11, 683-692. doi: $10.1038 / \mathrm{nn} .2124$

Czisch, M., Wetter, T.C., Kaufmann, C., Pollmächer, T., Holsboer, F., Auer, D.P., 2002. Altered processing of acoustic stimuli during sleep: Reduced auditory activation and visual deactivation detected by a combined fMRI/EEG study. Neuroimage 16, 251-258. doi:10.1006/nimg.2002.1071

Doria, V., Beckmann, C.F., Arichi, T., Merchant, N., Groppo, M., Turkheimer, F.E., Counsell, S.J., Murgasova, M., Aljabar, P., Nunes, R.G., Larkman, D.J., Rees, G., Edwards, A.D., 2010. Emergence of resting state networks in the preterm human brain. Proc. Natl. Acad.

Sci. U. S. A. 107, 20015-20. doi:10.1073/pnas.1007921107

Dunn, W., 2014. Sensory Profile 2 Manual.

Dunn, W., 1999. The Sensory Profiles.

Farmer, C.A., Chilakamarri, P., Thurm, A.E., Swedo, S.E., Holmes, G.L., Buckley, A.W., 2018. Spindle activity in young children with autism, developmental delay, or typical development. Neurology 91, e112-e122. doi:10.1212/WNL.0000000000005759

Ferradal, S.L., Gagoski, B., Jaimes, C., Yi, F., Carruthers, C., Vu, C., Litt, J.S., Larsen, R., Sutton, B., Grant, P.E., Zöllei, L., 2019. System-Specific Patterns of Thalamocortical Connectivity in Early Brain Development as Revealed by Structural and Functional MRI. Cereb. Cortex 29, 1218-1229. doi:10.1093/cercor/bhy028

Ferri, R., Elia, M., Agarwal, N., Lanuzza, B., Musumeci, S.A., Pennisi, G., 2003. The mismatch 
negativity and the P3a components of the auditory event-related potentials in autistic lowfunctioning subjects. Clin. Neurophysiol. 114, 1671-80.

Gazestani, V.H., Pramparo, T., Nalabolu, S., Kellman, B.P., Murray, S., Lopez, L., Pierce, K., Courchesne, E., Lewis, N.E., 2019. A perturbed gene network containing PI3K-AKT, RAS-ERK and WNT- $\beta$-catenin pathways in leukocytes is linked to ASD genetics and symptom severity. Nat. Neurosci. 22, 1624-1634. doi:10.1038/s41593-019-0489-x

Getahun, D., Fassett, M., Peltier, M., Wing, D., Xiang, A., Chiu, V., Jacobsen, S., 2017. Association of Perinatal Risk Factors with Autism Spectrum Disorder. Am. J. Perinatol. 34, 295-304. doi:10.1055/s-0036-1597624

Gomot, M., Bernard, F.A., Davis, M.H., Belmonte, M.K., Ashwin, C., Bullmore, E.T., BaronCohen, S., 2006. Change detection in children with autism: an auditory event-related fMRI study. Neuroimage 29, 475-484.

Green, S.A., Hernandez, L., Bookheimer, S.Y., Dapretto, M., 2017. Reduced modulation of thalamocortical connectivity during exposure to sensory stimuli in ASD. Autism Res. 10, 801-809. doi:10.1002/aur.1726

Green, S.A., Hernandez, L., Lawrence, K.E., Liu, J., Tsang, T., Yeargin, J., Cummings, K., Laugeson, E., Dapretto, M., Bookheimer, S.Y., 2019. Distinct Patterns of Neural Habituation and Generalization in Children and Adolescents With Autism With Low and High Sensory Overresponsivity. Am. J. Psychiatry appi.ajp.2019.1. doi:10.1176/appi.ajp.2019.18121333

Green, S.A., Hernandez, L., Tottenham, N., Krasileva, K., Bookheimer, S.Y., Dapretto, M., 2015. Neurobiology of Sensory Overresponsivity in Youth With Autism Spectrum Disorders. JAMA psychiatry 72, 778-86. doi:10.1001/jamapsychiatry.2015.0737

Gregory, A.M., Cousins, J.C., Forbes, E.E., Trubnick, L., Ryan, N.D., Axelson, D.A., Birmaher, B., Sadeh, A., Dahl, R.E., 2011. Sleep items in the child behavior checklist: A comparison with sleep diaries, actigraphy, and polysomnography. J. Am. Acad. Child Adolesc. Psychiatry 50, 499-507. doi:10.1016/j.jaac.2011.02.003

Grove, J., Ripke, S., Als, T.D., Mattheisen, M., Walters, R.K., Won, H., Pallesen, J., Agerbo, E., Andreassen, O.A., Anney, R., Awashti, S., Belliveau, R., Bettella, F., Buxbaum, J.D., Bybjerg-Grauholm, J., Bækvad-Hansen, M., Cerrato, F., Chambert, K., Christensen, J.H., Churchhouse, C., Dellenvall, K., Demontis, D., De Rubeis, S., Devlin, B., Djurovic, S., Dumont, A.L., Goldstein, J.I., Hansen, C.S., Hauberg, M.E., Hollegaard, M. V., Hope, S., Howrigan, D.P., Huang, H., Hultman, C.M., Klei, L., Maller, J., Martin, J., Martin, A.R., Moran, J.L., Nyegaard, M., Nærland, T., Palmer, D.S., Palotie, A., Pedersen, C.B., Pedersen, M.G., DPoterba, T., Poulsen, J.B., Pourcain, B.S., Qvist, P., Rehnström, K., Reichenberg, A., Reichert, J., Robinson, E.B., Roeder, K., Roussos, P., Saemundsen, E., Sandin, S., Satterstrom, F.K., Davey Smith, G., Stefansson, H., Steinberg, S., Stevens, C.R., Sullivan, P.F., Turley, P., Walters, G.B., Xu, X., Wray, N.R., Trzaskowski, M., Byrne, E.M., Abdellaoui, A., Adams, M.J., Air, T.M., Andlauer, T.F.M., Bacanu, S.A., Beekman, A.T.F., Bigdeli, T.B., Binder, E.B., Blackwood, D.H.R., Bryois, J., Buttenschøn, H.N., Cai, N., Castelao, E., Clarke, T.K., Coleman, J.R.I., Colodro-Conde, L., Couvy-Duchesne, B., Craddock, N., Crawford, G.E., Davies, G., Deary, I.J., Degenhardt, F., Derks, E.M., Direk, N., Dolan, C. V., Dunn, E.C., Eley, T.C., Escott-Price, V., Kiadeh, F.F.H., Finucane, H.K., Forstner, A.J., Frank, J., Gaspar, H.A., Gill, M., Goes, F.S., Gordon, S.D., Hall, L.S., Hansen, T.F., Herms, S., Hickie, I.B., Hoffmann, P., Homuth, G., Horn, C., Hottenga, J.J., Ising, M., Jansen, R., Jorgenson, E., Knowles, J.A., Kohane, I.S., Kraft, J., Kretzschmar, 
W.W., Krogh, J., Kutalik, Z., Li, Y., Lind, P.A., MacIntyre, D.J., MacKinnon, D.F., Maier, R.M., Maier, W., Marchini, J., Mbarek, H., McGrath, P., McGuffin, P., Medland, S.E., Mehta, D., Middeldorp, C.M., Mihailov, E., Milaneschi, Y., Milani, L., Mondimore, F.M., Montgomery, G.W., Mostafavi, S., Mullins, N., Nauck, M., Ng, B., Nivard, M.G., Nyholt, D.R., O’Reilly, P.F., Oskarsson, H., Owen, M.J., Painter, J.N., Peterson, R.E., Pettersson, E., Peyrot, W.J., Pistis, G., Posthuma, D., Quiroz, J.A., Rice, J.P., Riley, B.P., Rivera, M., Mirza, S.S., Schoevers, R., Schulte, E.C., Shen, L., Shi, J., Shyn, S.I., Sigurdsson, E., Sinnamon, G.C.B., Smit, J.H., Smith, D.J., Streit, F., Strohmaier, J., Tansey, K.E., Teismann, H., Teumer, A., Thompson, W., Thomson, P.A., Thorgeirsson, T.E., Traylor, M., Treutlein, J., Trubetskoy, V., Uitterlinden, A.G., Umbricht, D., Van der Auwera, S., van Hemert, A.M., Viktorin, A., Visscher, P.M., Wang, Y., Webb, B.T., Weinsheimer, S.M., Wellmann, J., Willemsen, G., Witt, S.H., Wu, Y., Xi, H.S., Yang, J., Zhang, F., Arolt, V., Baune, B.T., Berger, K., Boomsma, D.I., Cichon, S., Dannlowski, U., de Geus, E.J.C., DePaulo, J.R., Domenici, E., Domschke, K., Esko, T., Grabe, H.J., Hamilton, S.P., Hayward, C., Heath, A.C., Kendler, K.S., Kloiber, S., Lewis, G., Li, Q.S., Lucae, S., Madden, P.A.F., Magnusson, P.K., Martin, N.G., McIntosh, A.M., Metspalu, A., MüllerMyhsok, B., Nöthen, M.M., O’Donovan, M.C., Paciga, S.A., Pedersen, N.L., Penninx, B.W.J.H., Perlis, R.H., Porteous, D.J., Potash, J.B., Preisig, M., Rietschel, M., Schaefer, C., Schulze, T.G., Smoller, J.W., Tiemeier, H., Uher, R., Völzke, H., Weissman, M.M., Lewis, C.M., Levinson, D.F., Breen, G., Agee, M., Alipanahi, B., Auton, A., Bell, R.K., Bryc, K., Elson, S.L., Fontanillas, P., Furlotte, N.A., Hromatka, B.S., Huber, K.E., Kleinman, A., Litterman, N.K., McIntyre, M.H., Mountain, J.L., Noblin, E.S., Northover, C.A.M., Pitts, S.J., Sathirapongsasuti, J.F., Sazonova, O. V., Shelton, J.F., Shringarpure, S., Tung, J.Y., Vacic, V., Wilson, C.H., Stefansson, K., Geschwind, D.H., Nordentoft, M., Hougaard, D.M., Werge, T., Mors, O., Mortensen, P.B., Neale, B.M., Daly, M.J., Børglum, A.D., 2019. Identification of common genetic risk variants for autism spectrum disorder. Nat. Genet. 51, 431-444. doi:10.1038/s41588-019-0344-8

Hadders-Algra, M., 2018. Early human brain development: Starring the subplate. Neurosci. Biobehav. Rev. 92, 276-290. doi:10.1016/J.NEUBIOREV.2018.06.017

Hale, J.R., White, T.P., Mayhew, S.D., Wilson, R.S., Rollings, D.T., Khalsa, S., Arvanitis, T.N., Bagshaw, A.P., 2016. Altered thalamocortical and intra-thalamic functional connectivity during light sleep compared with wake. Neuroimage 125, 657-667. doi:10.1016/J.NEUROIMAGE.2015.10.041

Hoerder-Suabedissen, A., Molnár, Z., 2015. Development, evolution and pathology of neocortical subplate neurons. Nat. Rev. Neurosci. 16, 133-46. doi:10.1038/nrn3915

Hoerder-Suabedissen, A., Oeschger, F.M., Krishnan, M.L., Belgard, T.G., Wang, W.Z., Lee, S., Webber, C., Petretto, E., Edwards, A.D., Molnár, Z., 2013. Expression profiling of mouse subplate reveals a dynamic gene network and disease association with autism and schizophrenia. Proc. Natl. Acad. Sci. U. S. A. 110, 3555-60. doi:10.1073/pnas.1218510110 Holiga, Š., Hipp, J.F., Chatham, C.H., Garces, P., Spooren, W., D’Ardhuy, X.L., Bertolino, A., Bouquet, C., Buitelaar, J.K., Bours, C., Rausch, A., Oldehinkel, M., Bouvard, M., Amestoy, A., Caralp, M., Gueguen, S., Ly-Le Moal, M., Houenou, J., Beckmann, C.F., Loth, E., Murphy, D., Charman, T., Tillmann, J., Laidi, C., Delorme, R., Beggiato, A., Gaman, A., Scheid, I., Leboyer, M., d'Albis, M.-A., Sevigny, J., Czech, C., Bolognani, F., Honey, G.D., Dukart, J., 2019. Patients with autism spectrum disorders display reproducible functional connectivity alterations. Sci. Transl. Med. 11, eaat9223. doi:10.1126/scitranslmed.aat9223 
Hudac, C.M., DesChamps, T.D., Arnett, A.B., Cairney, B.E., Ma, R., Webb, S.J., Bernier, R.A., 2018. Early enhanced processing and delayed habituation to deviance sounds in autism spectrum disorder. Brain Cogn 123, 110-119. doi:10.1016/j.bandc.2018.03.004

Hull, J. V, Jacokes, Z.J., Torgerson, C.M., Irimia, A., Van Horn, J.D., 2017. Resting-State Functional Connectivity in Autism Spectrum Disorders: A Review. Front Psychiatry 7, 205. doi:10.3389/fpsyt.2016.00205

Humphreys, J.S., Gringras, P., Blair, P.S., Scott, N., Henderson, J., Fleming, P.J., Emond, A.M., 2014. Sleep patterns in children with autistic spectrum disorders: A prospective cohort study. Arch. Dis. Child. 99, 114-118. doi:10.1136/archdischild-2013-304083

Hutsler, J.J., Avino, T., 2015. The Relevance of Subplate Modifications to Connectivity in the Cerebral Cortex of Individuals with Autism Spectrum Disorders, in: Recent Advances on the Modular Organization of the Cortex. Springer Netherlands, Dordrecht, pp. 201-224. doi:10.1007/978-94-017-9900-3_12

Hutsler, J.J., Casanova, M.F., 2015. Review: Cortical construction in autism spectrum disorder: Columns, connectivity and the subplate. Neuropathol. Appl. Neurobiol. 1-20. doi:10.1111/nan.12227

Hwang, K., Bertolero, M.A., Liu, W.B., D’Esposito, M., 2017. The Human Thalamus Is an Integrative Hub for Functional Brain Networks. J. Neurosci. 37, 5594-5607. doi:10.1523/JNEUROSCI.0067-17.2017

Iidaka, T., Kogata, T., Mano, Y., Komeda, H., 2019. Thalamocortical Hyperconnectivity and Amygdala-Cortical Hypoconnectivity in Male Patients With Autism Spectrum Disorder. Front. Psychiatry 10, 252. doi:10.3389/fpsyt.2019.00252

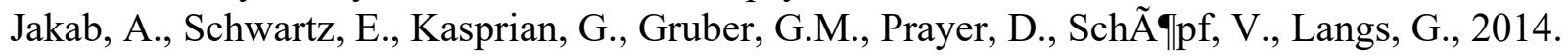
Fetal functional imaging portrays heterogeneous development of emerging human brain networks. Front. Hum. Neurosci. 8, 852. doi:10.3389/fnhum.2014.00852

Jan, J.E., Reiter, R.J., Wasdell, M.B., Bax, M., 2009. The role of the thalamus in sleep, pineal melatonin production, and circadian rhythm sleep disorders. J. Pineal Res. 46, 1-7. doi:10.1111/j.1600-079X.2008.00628.X

Kanold, P.O., 2019. The first cortical circuits: Subplate neurons lead the way and shape cortical organization. Neuroforum 25, 15-23. doi:10.1515/nf-2018-0010

Kanold, P.O., 2009. Subplate neurons: crucial regulators of cortical development and plasticity. Front. Neuroanat. 3, 16. doi:10.3389/neuro.05.016.2009

Kanold, P.O., 2003. Role of Subplate Neurons in Functional Maturation of Visual Cortical Columns. Science (80-. ). 301, 521-525. doi:10.1126/science. 1084152

Kanold, P.O., Deng, R., Meng, X., 2019. The integrative function of silent synapses on subplate neurons in cortical development and dysfunction. Front. Neuroanat. doi:10.3389/fnana.2019.00041

Kanold, P.O., Luhmann, H.J., 2010. The subplate and early cortical circuits. Annu. Rev. Neurosci. 33, 23-48. doi:10.1146/annurev-neuro-060909-153244

Kolesnik, A., Begum Ali, J., Gliga, T., Guiraud, J., Charman, T., Johnson, M.H., Jones, E.J.H., 2019. Increased cortical reactivity to repeated tones at 8 months in infants with later ASD. Transl. Psychiatry 9, 1-11. doi:10.1038/s41398-019-0393-x

Kostovic, I., Judas, M., 2010. The development of the subplate and thalamocortical connections in the human foetal brain. Acta Paediatr. 99, 1119-1127. doi:10.1111/j.16512227.2010.01811.x

Kostović, I., Judaš, M., Sedmak, G., 2011. Developmental history of the subplate zone, subplate 
neurons and interstitial white matter neurons: relevance for schizophrenia. Int. J. Dev.

Neurosci. 29, 193-205. doi:10.1016/j.ijdevneu.2010.09.005

Krakowiak, P., Goodlin-Jones, B., Hertz-Picciotto, I., Croen, L.A., Hansen, R.L., 2008. Sleep problems in children with autism spectrum disorders, developmental delays, and typical development: A population-based study. J. Sleep Res. 17, 197-206. doi:10.1111/j.13652869.2008.00650.x

Kumar, V.J., van Oort, E., Scheffler, K., Beckmann, C.F., Grodd, W., 2017. Functional anatomy of the human thalamus at rest. Neuroimage 147, 678-691.

doi:10.1016/J.NEUROIMAGE.2016.12.071

Lehoux, T., Carrier, J., Godbout, R., 2019. NREM sleep EEG slow waves in autistic and typically developing children: Morphological characteristics and scalp distribution. J. Sleep Res. 28, e12775. doi:10.1111/jsr.12775

Linke, A.C., Jao Keehn, R.J., Pueschel, E.B., Fishman, I., Müller, R.A., 2018. Children with ASD show links between aberrant sound processing, social symptoms, and atypical auditory interhemispheric and thalamocortical functional connectivity. Dev. Cogn. Neurosci. 29, 117-126. doi:10.1016/j.dcn.2017.01.007

Lombardo, M. V, Moon, H.M., Su, J., Palmer, T.D., Courchesne, E., Pramparo, T., 2018. Maternal immune activation dysregulation of the fetal brain transcriptome and relevance to the pathophysiology of autism spectrum disorder. Mol. Psychiatry 23, 1001-1013. doi:10.1038/mp.2017.15

Lord, C., Rutter, M., 2003. Social communication questionnaire (SCQ). WPS, Torrance, CA.

Lord, C., Rutter, M., DiLavore, P., Risi, S., Gotham, K., Bishop, S.L., 2012. Autism Diagnostic Observation Schedule - 2, 2nd ed. Western Psychological Services, Torrance (CA).

Luhmann, H.J., Kirischuk, S., Kilb, W., 2018. The Superior Function of the Subplate in Early Neocortical Development. Front. Neuroanat. 12, 97. doi:10.3389/fnana.2018.00097

MacDuffie, K.E., Shen, M.D., Dager, S.R., Styner, M.A., Kim, S.H., Paterson, S., Pandey, J., St. John, T., Elison, J.T., Wolff, J.J., Swanson, M.R., Botteron, K.N., Zwaigenbaum, L., Piven, J., Estes, A.M., 2020. Sleep Onset Problems and Subcortical Development in Infants Later Diagnosed With Autism Spectrum Disorder. Am. J. Psychiatry 177, 518-525. doi:10.1176/appi.ajp.2019.19060666

Mannion, A., Leader, G., 2014. Sleep Problems in Autism Spectrum Disorder: A Literature Review. Rev. J. Autism Dev. Disord. 1, 101-109. doi:10.1007/s40489-013-0009-y

Materna, S., Dicke, P.W., Thier, P., 2008. Dissociable roles of the superior temporal sulcus and the intraparietal sulcus in joint attention: a functional magnetic resonance imaging study. $\mathrm{J}$. Cogn. Neurosci. 20, 108-119.

Maximo, J.O., Kana, R.K., 2019. Aberrant "deep connectivity" in autism: A cortico-subcortical functional connectivity magnetic resonance imaging study. Autism Res. 12, 384-400. doi:10.1002/aur.2058

Mazzone, L., Postorino, V., Siracusano, M., Riccioni, A., Curatolo, P., 2018. The Relationship between Sleep Problems, Neurobiological Alterations, Core Symptoms of Autism Spectrum Disorder, and Psychiatric Comorbidities. J. Clin. Med. 7, 102. doi:10.3390/jcm7050102 McClendon, E., Shaver, D.C., Degener-O’Brien, K., Gong, X., Nguyen, T., HoerderSuabedissen, A., Molnár, Z., Mohr, C., Richardson, B.D., Rossi, D.J., Back, S.A., 2017. Transient Hypoxemia Chronically Disrupts Maturation of Preterm Fetal Ovine Subplate Neuron Arborization and Activity. J. Neurosci. 37, 11912-11929. doi:10.1523/JNEUROSCI.2396-17.2017 
McFadden, K., Minshew, N.J., 2013. Evidence for dysregulation of axonal growth and guidance in the etiology of ASD. Front. Hum. Neurosci. 7. doi:10.3389/fnhum.2013.00671

McQuillen, P.S., Sheldon, R.A., Shatz, C.J., Ferriero, D.M., 2003. Selective vulnerability of subplate neurons after early neonatal hypoxia-ischemia. J. Neurosci. 23, 3308-3315. doi:23/8/3308 [pii]

Mikhailova, A., Sunkara, N., McQuillen, P.S., 2017. Unbiased Quantification of Subplate Neuron Loss following Neonatal Hypoxia-Ischemia in a Rat Model. Dev. Neurosci. 39, 171-181. doi:10.1159/000460815

Mitra, A., Snyder, A.Z., Tagliazucchi, E., Laufs, H., Elison, J., Emerson, R.W., Shen, M.D., Wolff, J.J., Botteron, K.N., Dager, S., Estes, A.M., Evans, A.C., Gerig, G., Hazlett, H.C., Paterson, S.J., Schultz, R.T., Styner, M.A., Zwaigenbaum, L., Chappell, C., Estes, A., Shaw, D., Botteron, K., McKinstry, R., Constantino, J., Pruett, J., Schultz, R., Paterson, S., Collins, D.L., Pike, G.B., Fonov, V., Kostopoulos, P., Das, S., Styner, M., Gu, H., Schlaggar, B.L., Piven, J., Pruett, J.R., Raichle, M., 2017. Resting-state fMRI in sleeping infants more closely resembles adult sleep than adult wakefulness. PLoS One 12, e0188122. doi:10.1371/journal.pone.0188122

Mitra, A., Snyder, A.Z., Tagliazucchi, E., Laufs, H., Raichle, M.E., 2015. Propagated infra-slow intrinsic brain activity reorganizes across wake and slow wave sleep. Elife 4. doi:10.7554/eLife.10781.001

Mizuno, A., Villalobos, M.E., Davies, M.M., Dahl, B.C., Müller, R.-A., 2006. Partially enhanced thalamocortical functional connectivity in autism. Brain Res. 1104, 160-174. doi:10.1016/j.brainres.2006.05.064

Molnár, Z., Luhmann, H.J., Kanold, P.O., 2020. Transient cortical circuits match spontaneous and sensory-driven activity during development. Science 370. doi:10.1126/science.abb2153

Müller, R.-A., 2014. Anatomical and functional connectivity in autism spectrum disorders, in: Patel, V.B., Preedy, V.R. (Eds.), The Comprehensive Guide to Autism. Springer, New York, pp. 49-75.

Nagode, D.A., Meng, X., Winkowski, D.E., Smith, E., Khan-Tareen, H., Kareddy, V., Kao, J.P.Y., Kanold, P.O., 2017. Abnormal Development of the Earliest Cortical Circuits in a Mouse Model of Autism Spectrum Disorder. Cell Rep. 18, 1100-1108. doi:10.1016/j.celrep.2017.01.006

Nair, A., Carper, R.A., Abbott, A.E., Chen, C.P., Solders, S., Nakutin, S., Datko, M.C., Fishman, I., Müller, R.A., 2015. Regional specificity of aberrant thalamocortical connectivity in autism. Hum Brain Mapp 36, 4497-4511. doi:10.1002/hbm.22938

Nair, A., Treiber, J.M., Shukla, D.K., Shih, P., Müller, R.-A., 2013. Impaired thalamocortical connectivity in autism spectrum disorder: a study of functional and anatomical connectivity. Brain 136, 1942-55. doi:10.1093/brain/awt079

Nguyen, A.K.D., Murphy, L.E., Kocak, M., Tylavsky, F.A., Pagani, L.S., 2018. Prospective associations between infant sleep at 12 months and autism spectrum disorder screening scores at 24 months in a community-based birth cohort. J. Clin. Psychiatry 79. doi: $10.4088 /$ JCP.16m11127

O’Leary, D.D.M., Nakagawa, Y., 2002. Patterning centers, regulatory genes and extrinsic mechanisms controlling arealization of the neocortex. Curr. Opin. Neurobiol. doi:10.1016/S0959-4388(02)00285-4

Ozonoff, S., Young, G.S., Landa, R.J., Brian, J., Bryson, S., Charman, T., Chawarska, K., Macari, S.L., Messinger, D., Stone, W.L., Zwaigenbaum, L., Iosif, A.-M., 2015. Diagnostic 
stability in young children at risk for autism spectrum disorder: a baby siblings research consortium study. J. Child Psychol. Psychiatry. 56, 988-98. doi:10.1111/jcpp.12421

Page, J., Lustenberger, C., Fröhlich, F., 2020. Nonrapid eye movement sleep and risk for autism spectrum disorder in early development: A topographical electroencephalogram pilot study. doi:10.1002/brb3.1557

Picchioni, D., Pixa, M.L., Fukunaga, M., Carr, W.S., Horovitz, S.G., Braun, A.R., Duyn, J.H., 2014. Decreased connectivity between the thalamus and the neocortex during human nonrapid eye movement sleep. Sleep 37, 387-97. doi:10.5665/sleep.3422

Reynolds, A.M., Malow, B.A., 2011. Sleep and Autism Spectrum Disorders. Pediatr. Clin. North Am. 58, 685-698. doi:10.1016/j.pcl.2011.03.009

Reynolds, A.M., Soke, G.N., Sabourin, K.R., Hepburn, S., Katz, T., Wiggins, L.D., Schieve, L.A., Levy, S.E., 2019. Sleep Problems in 2- to 5-Year-Olds With Autism Spectrum Disorder and Other Developmental Delays. Pediatrics 143, e20180492. doi:10.1542/peds.2018-0492

Richdale, A.L., Schreck, K.A., 2009. Sleep problems in autism spectrum disorders: Prevalence, nature, \&amp; possible biopsychosocial aetiologies. Sleep Med. Rev. 13, 403-411. doi:10.1016/J.SMRV.2009.02.003

Rotem-Kohavi, N., Williams, L.J., Virji-Babul, N., Bjornson, B.H., Brain, U., Werker, J.F., Grunau, R.E., Miller, S.P., Oberlander, T.F., 2019. Alterations in Resting-State Networks Following In Utero Selective Serotonin Reuptake Inhibitor Exposure in the Neonatal Brain. Biol. psychiatry. Cogn. Neurosci. neuroimaging 4, 39-49. doi:10.1016/j.bpsc.2018.08.004

Sadeh, A., 2004. A brief screening questionnaire for infant sleep problems: validation and findings for an Internet sample. Pediatrics 113, e570-e577. doi:10.1542/peds.113.6.e570

Sandin, S., Lichtenstein, P., Kuja-Halkola, R., Hultman, C., Larsson, H., Reichenberg, A., 2017. The Heritability of Autism Spectrum Disorder. JAMA 318, 1182. doi:10.1001/jama.2017.12141

Schoen, S.A., Miller, L.J., Green, K.E., 2008. Pilot study of the sensory over-responsivity scales: Assessment and inventory. Am. J. Occup. Ther. 62, 393-406. doi:10.5014/ajot.62.4.393

Schulz, S.E., Stevenson, R.A., 2019. Differentiating between sensory sensitivity and sensory reactivity in relation to restricted interests and repetitive behaviours. Autism 136236131985040. doi:10.1177/1362361319850402

Schwartz, S., Shinn-Cunningham, B., Tager-Flusberg, H., 2018. Meta-analysis and systematic review of the literature characterizing auditory mismatch negativity in individuals with autism. Neurosci Biobehav Rev 87, 106-117. doi:10.1016/j.neubiorev.2018.01.008

Serati, M., Delvecchio, G., Orsenigo, G., Mandolini, G.M., Lazzaretti, M., Scola, E., Triulzi, F., Brambilla, P., 2019. The Role of the Subplate in Schizophrenia and Autism: A Systematic Review. Neuroscience 408, 58-67. doi:10.1016/j.neuroscience.2019.03.049

Sikora, D.M., Johnson, K., Clemons, T., Katz, T., 2012. The Relationship Between Sleep Problems and Daytime Behavior in Children of Different Ages With Autism Spectrum Disorders. Pediatrics 130, S83-S90. doi:10.1542/peds.2012-0900F

Sivertsen, B., Posserud, M.-B., Gillberg, C., Lundervold, A.J., Hysing, M., 2012. Sleep problems in children with autism spectrum problems: a longitudinal population-based study. Autism 16, 139-150. doi:10.1177/1362361311404255

Skåtun, K.C., Kaufmann, T., Brandt, C.L., Doan, N.T., Alnæs, D., Tønnesen, S., Biele, G., Vaskinn, A., Melle, I., Agartz, I., Andreassen, O.A., Westlye, L.T., 2018. Thalamo-cortical functional connectivity in schizophrenia and bipolar disorder. Brain Imaging Behav. 12, 
640-652. doi:10.1007/s11682-017-9714-y

Smith, S.M., Jenkinson, M., Woolrich, M.W., Beckmann, C.F., Behrens, T.E.J., Johansen-Berg, H., Bannister, P.R., De Luca, M., Drobnjak, I., Flitney, D.E., Niazy, R.K., Saunders, J., Vickers, J., Zhang, Y., De Stefano, N., Brady, J.M., Matthews, P.M., 2004. Advances in functional and structural MR image analysis and implementation as FSL. Neuroimage 23, S208-S219. doi:10.1016/j.neuroimage.2004.07.051

Spoormaker, V.I., Schroter, M.S., Gleiser, P.M., Andrade, K.C., Dresler, M., Wehrle, R., Samann, P.G., Czisch, M., 2010. Development of a large-scale functional brain network during human non-rapid eye movement sleep. J Neurosci 30, 11379-11387. doi:10.1523/JNEUROSCI.2015-10.2010

Steriade, M., McCormick, D., Sejnowski, T., 1993. Thalamocortical oscillations in the sleeping and aroused brain. Science (80-. ). 262, 679-685. doi:10.1126/science.8235588

Stoner, R., Chow, M.L., Boyle, M.P., Sunkin, S.M., Mouton, P.R., Roy, S., Wynshaw-Boris, A., Colamarino, S.A., Lein, E.S., Courchesne, E., 2014. Patches of disorganization in the neocortex of children with autism. N. Engl. J. Med. 370, 1209-19. doi:10.1056/NEJMoa1307491

Swanson, M.R., Shen, M.D., Wolff, Jason J., Elison, Jed T., Emerson, R.W., Styner, M.A., Hazlett, Heather C., Truong, K., Watson, L.R., Paterson, Sarah, Marrus, N., Botteron, K.N., Pandey, Juhi, Schultz, Robert T., Dager, S.R., Zwaigenbaum, Lonnie, Estes, A.M., Piven, Joseph, Piven, J., Hazlett, H. C., Chappell, C., Dager, S., Shaw, D., Botteron, K., McKinstry, R., Constantino, J., Pruett, J., Schultz, R. T., Pandey, J., Paterson, S., Zwaigenbaum, L., Elison, J. T., Wolff, J. J., Evans, A.C., Collins, D.L., Pike, G.B., Fonov, V., Kostopoulos, P., Das, S., Gerig, G., Styner, M., Gu, H., 2017. Subcortical Brain and Behavior Phenotypes Differentiate Infants With Autism Versus Language Delay. Biol. Psychiatry Cogn. Neurosci. Neuroimaging 2, 664-672. doi:10.1016/j.bpsc.2017.07.007 Tagliazucchi, E., Laufs, H., 2014. Decoding Wakefulness Levels from Typical fMRI RestingState Data Reveals Reliable Drifts between Wakefulness and Sleep. Neuron 82, 695-708. doi:10.1016/j.neuron.2014.03.020

Tagliazucchi, E., von Wegner, F., Morzelewski, A., Borisov, S., Jahnke, K., Laufs, H., 2012. Automatic sleep staging using fMRI functional connectivity data. Neuroimage 63, 63-72. doi:10.1016/j.neuroimage.2012.06.036

Thomason, M.E., Dassanayake, M.T., Shen, S., Katkuri, Y., Alexis, M., Anderson, A.L., Yeo, L., Mody, S., Hernandez-Andrade, E., Hassan, S.S., Studholme, C., Jeong, J.-W., Romero, R., 2013. Cross-hemispheric functional connectivity in the human fetal brain. Sci. Transl. Med. 5, 173ra24. doi:10.1126/scitranslmed.3004978

Thomason, M.E., Scheinost, D., Manning, J.H., Grove, L.E., Hect, J., Marshall, N., HernandezAndrade, E., Berman, S., Pappas, A., Yeo, L., Hassan, S.S., Constable, R.T., Ment, L.R., Romero, R., 2017. Weak functional connectivity in the human fetal brain prior to preterm birth. Sci. Rep. 7, 39286. doi:10.1038/srep39286

Toulmin, H., Beckmann, C.F., O’Muircheartaigh, J., Ball, G., Nongena, P., Makropoulos, A., Ederies, A., Counsell, S.J., Kennea, N., Arichi, T., Tusor, N., Rutherford, M.A., Azzopardi, D., Gonzalez-Cinca, N., Hajnal, J. V, Edwards, A.D., 2015. Specialization and integration of functional thalamocortical connectivity in the human infant. Proc. Natl. Acad. Sci. U. S. A. 112, 6485-6490. doi:10.1073/pnas.1422638112

Tzischinsky, O., Meiri, G., Manelis, L., Bar-Sinai, A., Flusser, H., Michaelovski, A., Zivan, O., Ilan, M., Faroy, M., Menashe, I., Dinstein, I., 2018. Sleep disturbances are associated with 
specific sensory sensitivities in children with autism. Mol. Autism 9, 22.

doi:10.1186/s13229-018-0206-8

Wess, J.M., Isaiah, A., Watkins, P. V, Kanold, P.O., 2017. Subplate neurons are the first cortical neurons to respond to sensory stimuli. Proc. Natl. Acad. Sci. U. S. A. 114, 12602-12607. doi:10.1073/pnas. 1710793114

White, N., Roddey, C., Shankaranarayanan, A., Han, E., Rettmann, D., Santos, J., Kuperman, J., Dale, A., 2010. PROMO: Real-time prospective motion correction in MRI using imagebased tracking. Magn. Reson. Med. 63, 91-105. doi:10.1002/mrm.22176

Whitfield-Gabrieli, S., Nieto-Castanon, A., 2012. Conn: A Functional Connectivity Toolbox for Correlated and Anticorrelated Brain Networks. Brain Connect. 2, 125-141. doi:10.1089/brain.2012.0073

Woodward, N.D., Giraldo-Chica, M., Rogers, B., Cascio, C.J., 2017. Thalamocortical dysconnectivity in autism spectrum disorder: An analysis of the Autism Brain Imaging Data Exchange. Biol Psychiatry Cogn Neurosci Neuroimaging 2, 76-84. doi:10.1016/j.bpsc.2016.09.002

Woodward, N.D., Karbasforoushan, H., Heckers, S., 2012. Thalamocortical dysconnectivity in schizophrenia. Am. J. Psychiatry 169, 1092-1099. doi:10.1176/appi.ajp.2012.12010056

Yoshimura, Y., Kikuchi, M., Hiraishi, H., Hasegawa, C., Takahashi, T., Remijn, G.B., Oi, M., Munesue, T., Higashida, H., Minabe, Y., 2016. Synchrony of auditory brain responses predicts behavioral ability to keep still in children with autism spectrum disorder: Auditoryevoked response in children with autism spectrum disorder. NeuroImage Clin. 12, 300-305. doi:10.1016/j.nicl.2016.07.009

Zou, Q.H., Zhu, C.Z., Yang, Y., Zuo, X.N., Long, X.Y., Cao, Q.J., Wang, Y.F., Zang, Y.F., 2008. An improved approach to detection of amplitude of low-frequency fluctuation (ALFF) for resting-state fMRI: Fractional ALFF. J. Neurosci. Methods 172, 137-141. doi:10.1016/j.jneumeth.2008.04.012

Zuo, X.-N., Di Martino, A., Kelly, C., Shehzad, Z.E., Gee, D.G., Klein, D.F., Castellanos, F.X., Biswal, B.B., Milham, M.P., 2010. The oscillating brain: complex and reliable. Neuroimage 49, 1432-45. doi:10.1016/j.neuroimage.2009.09.037 